\title{
The Ex-Factor: Examining the Gendered Effect of Divorce on Voter Turnout*
}

\author{
Sirus H. Dehdari ${ }^{1,3}$, Karl-Oskar Lindgren ${ }^{1}$, Sven Oskarsson ${ }^{1}$, and Kåre \\ Vernby $^{2}$
}

${ }^{1}$ Department of Government, Uppsala University, 75120 Uppsala, Sweden

${ }^{2}$ Department of Political Science, Stockholm University, 10691 Stockholm, Sweden

${ }^{3}$ SOFI, Stockholm University, 10691 Stockholm, Sweden

\begin{abstract}
The absence of a gendered analysis of the effect of marriage on voting is surprising, given researchers' cognizance of the heterogeneous effects of marriage on a range of other social outcomes. In this paper, we shed new light on spousal dependency by studying the gendered impact of marital disruption, in the form of divorce, on voter turnout. First, drawing on Swedish population-wide registry data, we use the differential timing of divorces in relation to general elections to generate more credible estimates of the causal effect of divorce on turnout. Second, although we find that both sexes are strongly and adversely affected by divorce, we show that the effect is much more pronounced for men. Specifically, the long-term effect is almost twice as large for men. Finally, we use these, as well as a variety of additional data, to show that the gendered effect of divorce is mainly driven by
\end{abstract}

*We wish to thank Rafaela Dancygier and seminar participants at Stockholm and Uppsala University for helpful comments and suggestions. 
asymmetrical spousal mobilization due to higher levels of voter turnout among women. 
For more than half a century, political scientists have documented the influence of major life-cycle events on political participation. Of particular interest to researchers in this field has been the institution of marriage and its impact on voter turnout. The literature goes back to Glaser (1959, p. 569) who argued that "voting turnout tends to be a joint household activity, with the members either voting or staying home as a unit." This idea of spousal mobilization implies that, all else being equal, married individuals will be more likely to vote than their unmarried counterparts.

In this paper, we shed new light on spousal dependency by studying the gendered impact of marital disruptions, in the form of divorce, on voter turnout. Previous studies have found higher turnout among married individuals (Cutts and Fieldhouse, 2009; Leighley and Nagler, 2013; Plutzer, 2002; Plutzer and Wiefek, 2006; Strate et al., 1989; Timpone, 1998; Wolfinger and Wolfinger, 2008, Wolfinger and Rosenstone, 1980), and some have also estimated a negative effect of divorce on the probability of voting (Bhatti et al., 2020, Kern, 2010; Stoker and Jennings, 1995: Wolfinger and Wolfinger, 2008).1 However, only in rare exceptions has the possibility of a gendered effect of individuals' marital status on voter turnout been raised 2

${ }^{1}$ Stoker and Jennings, 1995, Highton and Wolfinger, 2001 and Pacheco and Plutzer, 2007 are exceptions that contradict the finding of a uniform positive effect of marriage on turnout. ${ }^{2}$ Kern (2010) contains separate empirical analyses of the divorce effect by gender. Voorpostel and Coffé (2012) estimate gendered effects of divorce and separation on self-reported participation in Swiss referenda. Bellettini et al. (2020) study an Italian city where they find gendered effects of marriage but not divorce. 
This absence of a gendered analysis of the effect of divorce on voting is surprising, given researchers' cognizance of the heterogeneous effects of divorce on a range of other social outcomes. Research on heterosexual couples suggest that while both parties are adversely affected by divorce, the nature and extent of the impact differs between women and men. On the one hand, women's economic standard of living declines more than that of men in the wake of divorce (Bianchi et al., 1999; Smock et al., 1999; Weitzman, 1985). This suggests that the socio-economic consequences of divorce are such that we would expect women's turnout to be more adversely affected than that of men. In Rosentone's (1982, p. 26) words, when a person experiences economic adversity, their "scarce resources are spent on holding body and soul together 'surviving' rather than on remote concerns like politics. ${ }^{3}$

On the other hand, the most common rationale for expecting married individuals to be more likely to vote than their unmarried counterparts draws on the idea of spousal mobilization. On this view, interpersonal influence between partners in married couples induces a correlation between their likelihood of voting (Bhatti et al., 2020; Cutts and Fieldhouse, 2009; Frödin Gruneau, 2018; Leighley and Nagler, 2013, Stoker and Jennings, 1995; Timpone, 1998; Wolfinger and Wolfinger, 2008).4 Therefore, experiencing the loss of one's more politically active partner may cause one to become more passive, and recent ${ }^{3}$ For a seminal treatment of socio-economic status and its impact on political participation, see Verba et al., 1995.

${ }^{4}$ Frödin Gruneau (2018) argues that this effect is partly driven by spousal mobilization of the individuals who 'marry up' in socio-economic terms, and partly by assortative mating (see also Frödin Gruneau, 2020). 
research suggests that in the case of voting, the more active partner is often the woman. Specifically, historically lower among women than men due to the lingering effects of historical disenfranchisement (Franklin, 2004), during the recent decades women in said countries have generally exhibited higher levels of turnout (Carreras, 2018, Cascio and Shenhav, 2020, Coffé and Bolzendahl, 2010 Leighley and Nagler, 2013). In line with this and, more broadly, with research showing that for men marriage is associated with a greater adherence to social norms (Bersani et al., 2009; King et al., 2007; Umberson, 1987), one can therefore theorize that spousal influence will be asymmetrical, and that women are more likely to mobilize their partners to vote than are men. If this line of reasoning is correct, then, we should expect men's turnout to be more adversely affected by divorce than that of women.

The existing literature thus suggests that divorce among couples will cause a decrease in their voter participation. However, among heterosexual couples it is a priori unclear whether the effect is going to be more dramatic for men or for women. To the best of our knowledge, this paper is the first large-scale systematic attempt to test for the gendered effect of divorce on voter turnout. In order to avoid the potential selection problems inherent in comparing the turnout of divorcees to married couples, and to generate credibly causal estimates of the gendered effect of divorce, we draw on unique Swedish individual-level administrative data that cover three elections cycles and include the turnout of all eligible voters. Since the data contain detailed information on the timing of divorce, and since divorce timing is unrelated to the election cycle, we are able to estimate the causal effect of divorce on turnout.

Our results show that divorce has a substantial negative effect on the likelihood of voting 
that persists over many years. As a benchmark, consider the immigrant-native turnout gap, which has been cause for concern among political scientists (e.g., Bird et al., 2011). In our sample, the short-term divorce effect is $25 \%$ larger $5^{5}$ Most importantly, while we find that both sexes are adversely affected by divorce, we show that the effect is much more pronounced for men. Probing for the mechanism that underlies the gendered effect of divorce, we begin by examining the possibility that the divorce effect is driven by changes in socio-economic status and residential mobility. In line with previous research, the post-divorce standard of living declines considerably for both sexes, but more so for women than for men. Turning to residential mobility, the effects of divorce are also dramatic, but gender differences are small and inconsistent. We therefore conclude that while explanations centering on economic distress and residential mobility can help explain why couples' turnout decline following divorce, they fail to provide a rationale for the gendered nature of this effect.

We then move on to examine the possibility that the gendered effect of divorce is driven by asymmetrical spousal mobilization. To do this, we analyze the impact of marriage on voter turnout using the same technique as we did when analyzing the impact of divorce. Since Swedish couples tend to co-habit quite long before marrying, marriage constitutes a less clear life-cycle transition than divorce. However, although the effect is less dramatic than for divorce, the results are consistent with spousal mobilization in that marriage causes an increase in turnout. Moreover, as was the case for divorce, this effect is asymmetric and is more pronounced for men. This further supports the hypothesis that the gendered ${ }^{5}$ The short-term divorce effect is $8 \%$-points, whereas the immigrant-native turnout gap is $6.5 \%$. 
effect of divorce is mainly driven by asymmetrical spousal mobilization. We also show that the negative effect of divorce is larger for individuals with low levels of 'political capital,' which we capture by looking at pre-marriage levels of turnout as well as parental turnout. This is in particular true when an individual marries someone with higher levels of 'political capital'. Individuals who 'marry up', in the sense of marrying a partner with higher electoral participation, will experience a dramatic drop in turnout when the marriage is dissolved. And since more men than women 'marry up', the woman in a relationship will more often than not be the mobilizing agent, resulting in the observed gendered effect of marriage and divorce on turnout.

Our study advances existing literature in several ways. The first contribution is theoretical in nature, and concerns the assumption that both sexes will be similarly affected by marital disruptions. In fact, we show that existing theories of political participation do suggest that this will typically not be the case. Despite this, and even though researchers have long been cognizant of the heterogeneous effects of divorce on other social outcomes, previous work that has systematically explored the possibility of a gendered effect of marital status on individuals' voter turnout is exceedingly rare.

Second, our modelling strategy, which relies on detailed population-wide data on the timing of divorces and voter participation, allows us to estimate the within-couple causal impact of divorce on voting for up to seven years before and after the event. This strategy allows us to map out the full dynamic response to divorce and also avoids potential selection problems, not the least those inherent in comparing the turnout of divorcees to married 
couples.

Finally, much of previous research has focused on comparing the voter turnout of married individuals to everyone else, thus ignoring the heterogeneity of the unmarried group, which comprises both those who have never married and the divorced and widowed. There are some exceptions, such as Wolfinger and Wolfinger (2008), who found significant differences between these different types of unmarried individuals with divorcees exhibiting the lowest levels of turnout (see also, Stoker and Jennings, 1995). While we analyze both the impact of divorce and marriage, the richness of our population-wide data allows us the precision to concentrate our analysis on divorce, which is often a more discrete and dramatic life-cycle event than marriage. ${ }^{6}$

\section{Existing Research}

Existing research has, with little exception, found turnout to be higher among married individuals (Cutts and Fieldhouse, 2009, Leighley and Nagler, 2013, Plutzer, 2002, Plutzer and Wiefek, 2006, Strate et al., 1989; Timpone, 1998; Wolfinger and Wolfinger, 2008; Wolfinger and Rosenstone, 1980) and that marital disruptions, caused by divorce or the death of a spouse, have a negative effect on the probability of voting (Bhatti et al., 2020, Hobbs et al., 2014; Kern, 2010; Stoker and Jennings, 1995; Wolfinger and Wolfinger, 2008). However, the possibility of a gendered effect of individuals' marital status on voter turnout has rarely ${ }^{6}$ On the effects of widowhood, see Hobbs et al., 2014, who find a persistent decrease in turnout in a large sample of Californian voters. 
been raised. This is surprising, given that the two main proposed theoretical mechanisms underlying the impact of marital status on turnout are distinctly gendered.

The first of these proposed mechanisms implies that marital status will be more consequential for women's turnout than for men's. In the words of Wolfinger and Wolfinger, 2008, "[d]ivorced and, to a lesser extent, widowed people fare worse than their married and never-married peers on a variety of social indicators (...) that are related to voter turnout." And while both women and men suffer significant socio-economic consequences from divorce, women's economic standard of living declines more in the wake of divorce (Bianchi et al.,

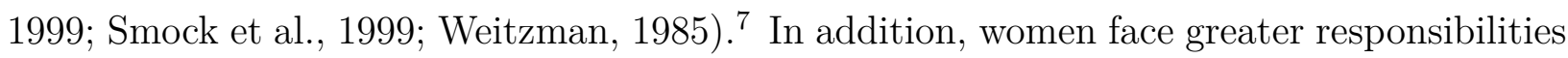
as single parents (Leopold, 2018), and are, according to some research, more likely to move after a divorce (Mulder and Wagner, 2010).

In view of this, and given the prominence of resource-based explanations for political participation (Rosenstone, 1982; Verba et al., 1995), one possible expectation would be that women's turnout will be more adversely affected by marital disruption than that of men. In the words of Kern (2010, p. 250), "[n]ewly divorced or widowed individuals are forced to make substantial adjustments in their personal lives that might crowd out participation in politics for a number of reasons (...) One would therefore expect the economic distress that often follows transitions out of marriage, especially among women, to reduce political participation." To this, Voorpostel and Coffé (2012, p. 30) add that "since women typically have custody of children, they have less time to participate in political and social life" (cf. ${ }^{7}$ However, it has been argued that the magnitude of the effect varies across countries (De Vaus et al., 2017). 
Shore, 2020).

The second proposed mechanism underlying the impact of marital status on turnout draws on the idea of spousal mobilization. On this account, married individuals are more likely to vote than their unmarried counterparts because of interpersonal influence between partners (Bhatti et al., 2020; Cutts and Fieldhouse, 2009; Glaser, 1959; Leighley and Nagler, 2013 Stoker and Jennings, 1995; Timpone, 1998 Wolfinger and Wolfinger, 2008) 8 This spillover-effect may exist because partners remind each other to vote, or go to the polls together (Bhatti et al., 2020), thus reducing the information costs of voting and also increasing the satisfaction derived from the act itself. The spill-over effect may also exist because partners exert normative pressure on each other (Blais et al., 2019). In the words of Abrams et al. (2011, p. 234), "if politics is seen as important during an election period in one's network of friends and family, then voting gains social approval and not voting leads to social disapproval."

Returning to the specific issue at hand, the spousal mobilization hypothesis implies that experiencing the loss of one's more politically active partner may cause one to become more passive. In other words, the detrimental effects of divorce should be more salient for those who have 'married up'? 9 While there is a considerable degree of cross-country variation, ${ }^{8}$ The existence of within-family spillover effects has been documented in get-out-the-vote experiments (Foos and De Rooij, 2017; Nickerson, 2008).

${ }^{9}$ See Frödin Gruneau (2018, p. 55) for a study that argues that a large part of the turnoutenhancing effect of marriage is driven by "low-educated individuals who have a highly educated partner." 
recent research suggests that in the case of voting, the more active partner is often the woman. Historically, turnout in many democratic countries was lower among women than men, perhaps due to the lingering effects of female disenfranchisement (Franklin, 2004). More recently, however, women have generally exhibited higher levels of turnout in many democratic countries (Carreras, 2018; Cascio and Shenhav, 2020; Coffé and Bolzendahl, 2010, Leighley and Nagler, 2013). One potential explanation for this can be found in psychological research on personality traits, which has found that women consistently exhibit higher degrees of conscientiousness (Schmitt et al., 2008). This trait is in turn related to greater adherence to norms, such as the one that states that it is a civic duty to vote (Gallego and Oberski, 2012) 10 Consequently, Carreras (2018, p. 40) argues that "these personality differences are critical to explain why women are more likely to go to the polls on Election Day." All this suggests that spousal influence will be asymmetrical. While the mobilizing agent in a heterosexual couple could historically be assumed to be the man (cf. Glaser, 1959), today women are more likely to mobilize their partners to vote. Thus, when women vote more than men, we should expect men's turnout to be more adversely affected by divorce than that of women.

Given the above, it is surprising that there are only a couple of studies that examine the gendered effect of divorce and separation on political participation. Kern (2010) utilizes the British Household Panel Survey to examine the impact of divorce on, among other

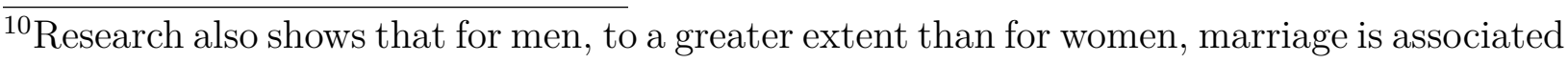
with a greater adherence to social norms (Bersani et al., 2009; King et al., 2007; Umberson, 1987). 
outcomes, turnout. Kern presents separate estimates for women and men, and while they are rather imprecise - in all likelihood due to data limitations - the magnitudes of these effects do not appear to differ substantially. Voorpostel and Coffé (2012) instead use the Swiss Household Panel, and find that women's self-reported participation in referenda falls in the wake of divorce or separation. In both studies, the authors had expected a more negative effect of divorce and separation for women, because women fare worse on a number of socio-demographic indicators related to turnout.

However, while we should be cautious in overinterpreting the results from a few studies that rely on smaller data sets than the one used here, the results, if taken together, are more in line with the theoretical accounts emphasizing spousal mobilization than those emphasizing socio-demographics. Specifically, while women's turnout in many democratic countries has surpassed that of men during recent decades, this is not true of the two countries studied. In Great Britain, voter turnout is very similar across genders, and we would therefore not expect gendered spousal mobilization. In Switzerland, where turnout is still higher among men (perhaps due to the late enfranchisement of women), spousal mobilization implies a more negative effect of divorce on women's voter participation. In a new study of voters in an Italian city, finally, Bellettini et al. (2020) find that marriage has a greater positive impact on voter turnout among men, while there is little evidence of a gendered divorce effect. In their sample, women vote slightly more than do men in the age span where individuals typically get married.

As we shall see in the next section, Sweden, which is the focus of the following empirical 
analysis, exemplifies the broader trend toward higher turnout among women than among men. If spousal mobilization is the main driver, men's turnout in Sweden should fall more in the wake of divorce than that of their female partners. If, on the other hand, sociodemographic changes are the main explanation for the divorce effect, the turnout of women should be more adversely affected than that of men.

\section{Institutional Setting, Data, and Method}

Like in many other Western countries, divorces in Sweden became increasingly common during the course of the last century. The right to no-fault divorce was introduced in Sweden already in 1915. Divorce rates increased gradually, but fairly slowly during the first half of the twentieth century. However, in the mid-1960s, partly as a result of progress in women's social and economic emancipation, divorce rates began to rise very rapidly. Between 1965 and 1975, Swedish divorce rates more than doubled, going from about 5 divorces per 1000 married women to more than 12 divorces per 1000. Among the couples marrying in the 1970s, almost 40 percent divorced within 25 years (Stanfors et al., 2020). In recent decades divorce rates in Sweden have been fairly stable, currently standing at about 13.8 divorces per 1000 married women.

Elections to the Swedish Parliament are held in September every fourth year, and all Swedish citizens aged 18 and older are eligible to vote. By international standards, Swedish voter turnout is fairly high. In recent decades, overall turnout has varied between 80 and 90 percent. From the 1980s, average turnout for women has been slightly higher than 
that for men (Statistics Sweden, 2012). However, the gender differences in voter turnout become more marked if we zoom in on turnout for women and men in different age groups as in Figure 1. The graph displays average turnout by gender and age in the three general

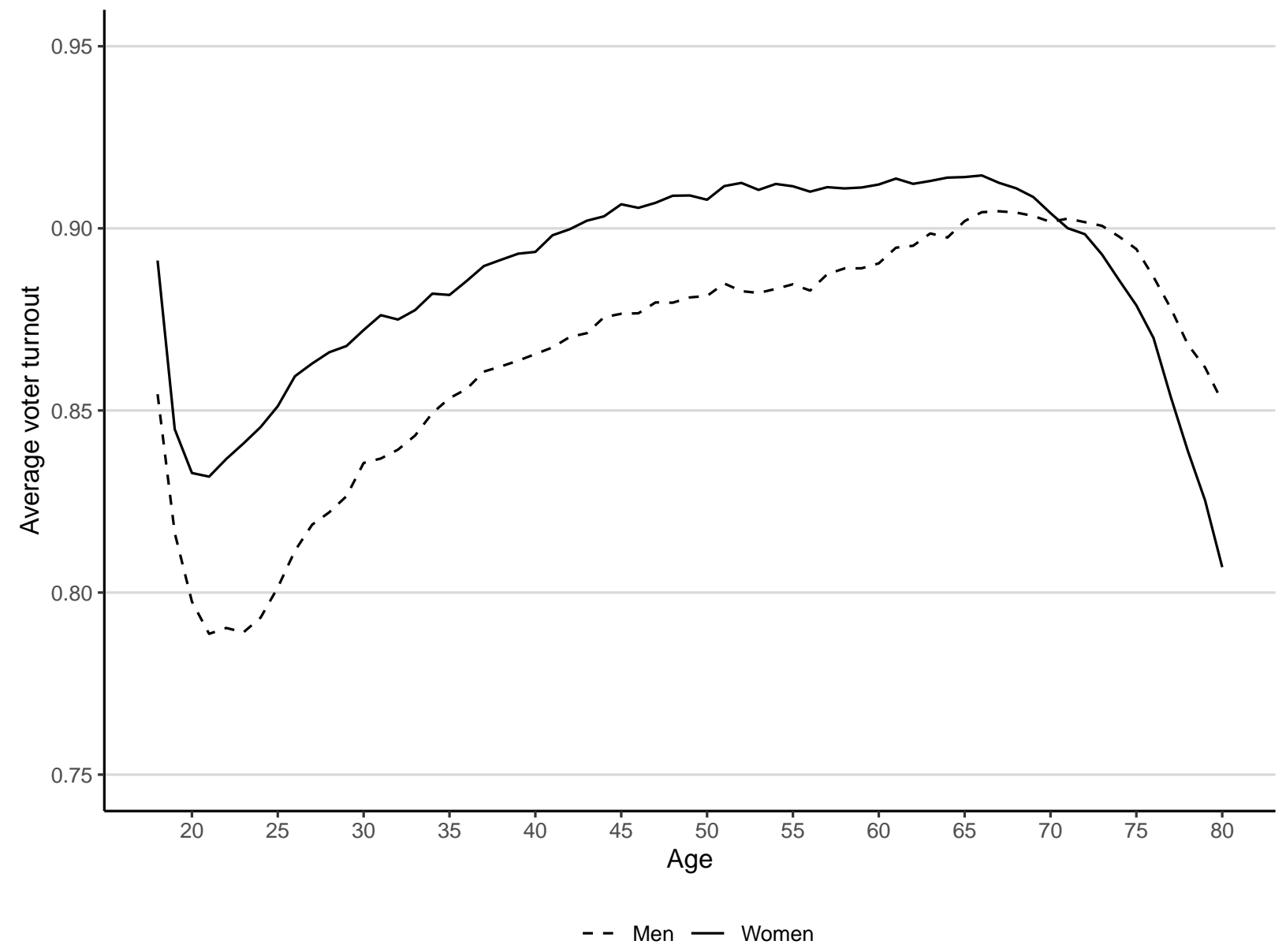

Figure 1: Turnout by Gender and Age

elections for which we have access to individual-level turnout data for the entire electorate, i.e., 1994, 2010, and 2018. As can be seen, women's turnout lies clearly above that of men for all but the very oldest age groups. The reversal of the relationship at the older ages is in all likelihood due to a combination of a cohort effect - the individuals in the oldest 
age groups were socialized into voting at a time when men voted more than women - and gender differences in mortality patterns. From the perspective of this study, however, the key insight from Figure 1 is that the average turnout is higher for women than for men in the age-span during which divorces usually occur.

Turning to a more detailed discussion of the data at our disposal, it mostly derives from various public registers maintained by Statistics Sweden. Through these registers, we have access to information on a large set of demographic and socio-economic indicators as well as to the start and, whenever applicable, end dates of all marriages. We can also match married individuals to their spouses through household identifiers. The end date of a marriage in the administrative registers records the date when the marriage was legally dissolved. However, for couples who live together with children that are 16 years or younger, there is a waiting period of six months between the filing of a divorce and its completion. We therefore predate the divorce data of these couples in our data with six months.

These data have then been matched to turnout data from the three general elections held in 1994, 2010, and 2018. For these three elections, individual-level data on voter turnout have been made available through digitization of the publicly available election rolls. The turnout data cover more than $90 \%$ of the electorate for the elections in questions, and previous research has shown that the digitization procedure being used provides highly reliable results (Lindgren et al., 2019).

To identify the impact of a divorce on the turnout of women and men, we will estimate 
a dynamic linear probability model of the following form:

$$
y_{i, c, t}=\sum_{k=-7}^{7} \beta_{k}^{g} D_{c, t}^{k}+\alpha_{1}^{g} D_{c, t}^{k \leq-8}+\alpha_{2}^{g} D_{c, t}^{k \geq 8}+\theta^{g} \boldsymbol{X}_{i, c, t}+\eta_{c}+\gamma \bar{y}_{g, c, t}+\epsilon_{i, c, t},
$$

where $y_{i, c, t}$ is turnout of individual $i$, in couple $c$, in election $t . D_{c, t}^{k}$ refers to a set of dummy variables set equal to one if an individual divorced $k$ years before an election (negative values of $k$ indicate that the divorce is to take place $k$ years after the election). The superscript $g$ attached to the coefficients of these indicators indicate that the divorce effect is allowed to differ by the gender of the individual. For reasons of statistical precision, we estimate a joint effect for divorces taking place more than 7 years before $\left(\alpha_{1}^{g}\right)$ or after $\left(\alpha_{2}^{g}\right)$ the election, respectively. In estimating this model, we will use $k=-3$ as the reference category, i.e., all estimates will be presented in relation to the turnout three years before a divorce.

Apart from the variables that capture the impact of divorce timing, the model also includes some additional controls. The vector $\boldsymbol{X}_{i, c, t}$ comprises a small set of predetermined individual characteristics, such as sex, years of education, and immigrant background, whereas $\eta_{c}$ denotes a full set of couple fixed effects. In studying voter turnout, it is fairly standard to control for age and election year fixed effects. However, in the presence of the couple fixed effects, the election year variable will be perfectly collinear with the divorce timing variable. If we instead replace the couple specific effects with individual fixed effects, as will be done as a robustness check, the age effects too will become perfectly collinear with divorce timing. To circumvent this problem, we instead add a control for expected turnout given an individual's birth cohort, sex, and the year of election $\left(\bar{y}_{g, c, t}\right)$. More precisely, we 
do this by calculating the mean turnout in the entire electorate for all unique combinations of birth year, sex, and election year and add this average as a control to the model. This procedure is akin to residualize the dependent variable with respect to the three variables used to construct the groups. By adding this control to the model, we can thus adjust for the impact of age and election year without running into any collinearity problems. The approach rests on the assumption that the age and election year fixed effects are the same for the population of divorcees as for the electorate as a whole.

Moreover, to avoid the complications caused by individuals with multiple divorces, we will focus on individuals who divorced exactly one time during the period 1985-2019. After excluding individuals with missing data on any of our key variables, we are left with a sample of 1,520,668 observations relating to 709,118 unique individuals in 354,559 different couples.

Table 1: Descriptive Statistics

\begin{tabular}{lrrrrr}
\hline & \multicolumn{2}{c}{ Men } & & \multicolumn{2}{c}{ Women } \\
\cline { 2 - 3 } \cline { 5 - 6 } & Mean & SD. & & Mean & SD. \\
\hline Turnout & 0.86 & 0.35 & & 0.88 & 0.32 \\
Years of Education & 11.75 & 2.56 & & 12.12 & 2.47 \\
Immigrant Background & 0.23 & 0.42 & & 0.25 & 0.43 \\
Age at Election & 51.27 & 12.43 & & 48.63 & 12.34 \\
Age at Divorce & 44.08 & 9.52 & & 41.40 & 9.37 \\
Year of Divorce & 2002.24 & 9.60 & 2002.24 & 9.60 \\
\hline
\end{tabular}

In Table 1, we present some basic descriptive statistics for our main sample, divided by sex. Voter turnout in general elections is high in Sweden, and in our sample the average turnout is 86 percent for men and 88 percent for women. The average number of years of schooling is slightly below 12 years for men and slightly above 12 years for women, and 
about a quarter of our sample has immigrant background, which here means that either the individuals themselves or at least one of their parents were born abroad. The average age when experiencing a divorce is 44 years for men and 41 years for women.

\section{Is the Divorce Effect Gendered?}

In analyzing how divorce affects voter turnout among men and women, it is illuminating to begin by looking at the bivariate relationship between turnout and divorce timing. To this end, Figure 2 displays average voter turnout by month since divorce at election time. For instance, turnout at month 12 is the average turnout for those that divorced 12 months before the election, and turnout in month -12 is the average turnout for those experiencing a divorce 12 months after the election.

As can be seen, married women and men have similar turnout rates before the divorce. For instance, in elections occurring three years prior to a divorce, the average turnout is about 90 percent among women as well as men. Turnout then starts to decline for both sexes. For women and men divorcing right around the time of an election, the turnout rates are only about 78 and 76 percent, respectively. Once the divorce has taken place, turnout rates start to rise again, but as can be seen they remain below their pre-divorce levels still seven years after the divorce.

The pattern displayed in Figure 2 suggests three important findings. First, a divorce has a substantial negative impact on voter turnout for both women and men, and this effect starts to materialize already 2-3 years prior to the actual divorce, although it is most marked 


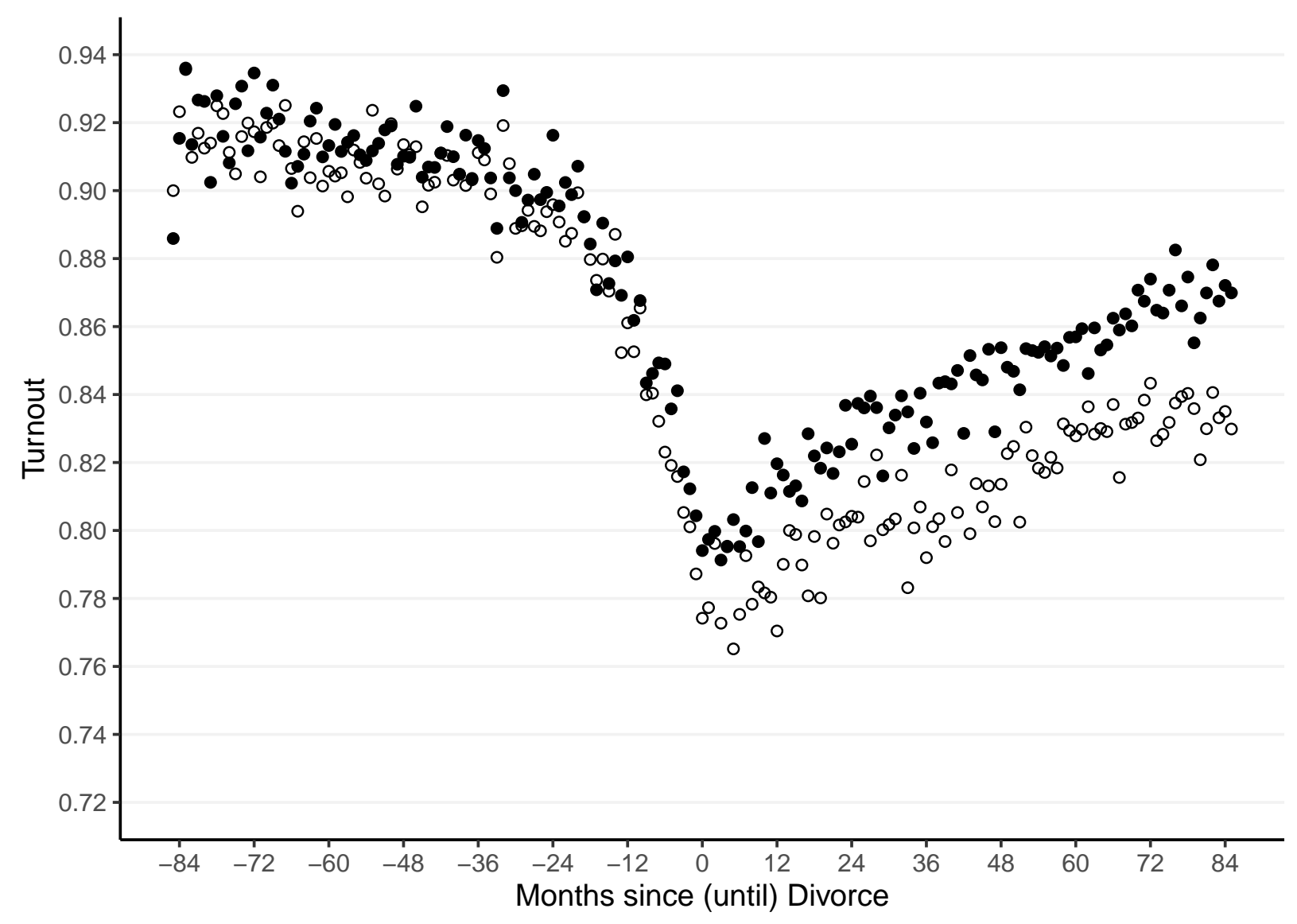

$\circ$ Men $\bullet$ Women

Figure 2: Turnout and Time since Divorce

right around the time of the divorce. Second, the reduction in turnout seems to be fairly long-lasting as it is clearly visible still seven years after the divorce. Third, whereas a divorce is associated with lower turnout rates among both sexes, men seem to experience a larger drop in turnout when going through a divorce.

To examine whether these findings hold up to closer scrutiny, we next estimate the regression model described in equation (1) using yearly data. One important advantage of the regression framework is that it allows us to account for the impact of age and election- 
year effects. Equally important, the inclusion of couple-fixed effects means that the divorce effect will be entirely identified from the within couple variation in voter turnout. That is, the couple-fixed effects will effectively control for all factors that remain constant over time for the couples going through a divorce. In all models, we include controls for sex, immigrant background, and years of schooling.

The upper panel of Figure 3 shows estimated divorce effects for women (solid line) and men (dashed line), respectively, based on our regression model. Since Figure 2 indicated that turnout rates start to decline already a couple of years before the divorce, we use the year -3 as our reference category. Hence, all effects are measured in comparison to turnout in elections taking place three years prior to the divorce.

Overall, the regression results mimic those of the bivariate analysis. We observe stable turnout levels for both sexes until three years before the divorce, then turnout starts to decline. If we compare turnout in the year of the divorce to turnout three years prior to the divorce, the drop in turnout is about 7.5 percentage points for women and 8.5 percentage points for men. As time passes, the turnout rates gradually start to increase again, but the recovery is faster for women than for men. Seven years after the divorce, women are about 3 percentage points less likely to vote than they were as married, whereas the corresponding figure for men is about 5.5 percentage points.

The regression results thus corroborate the finding that men's turnout is more adversely affected by a divorce. To further illustrate this, the lower panel of Figure 1 shows the differences in the divorce effects for women and men together with $95 \%$ confidence intervals. 

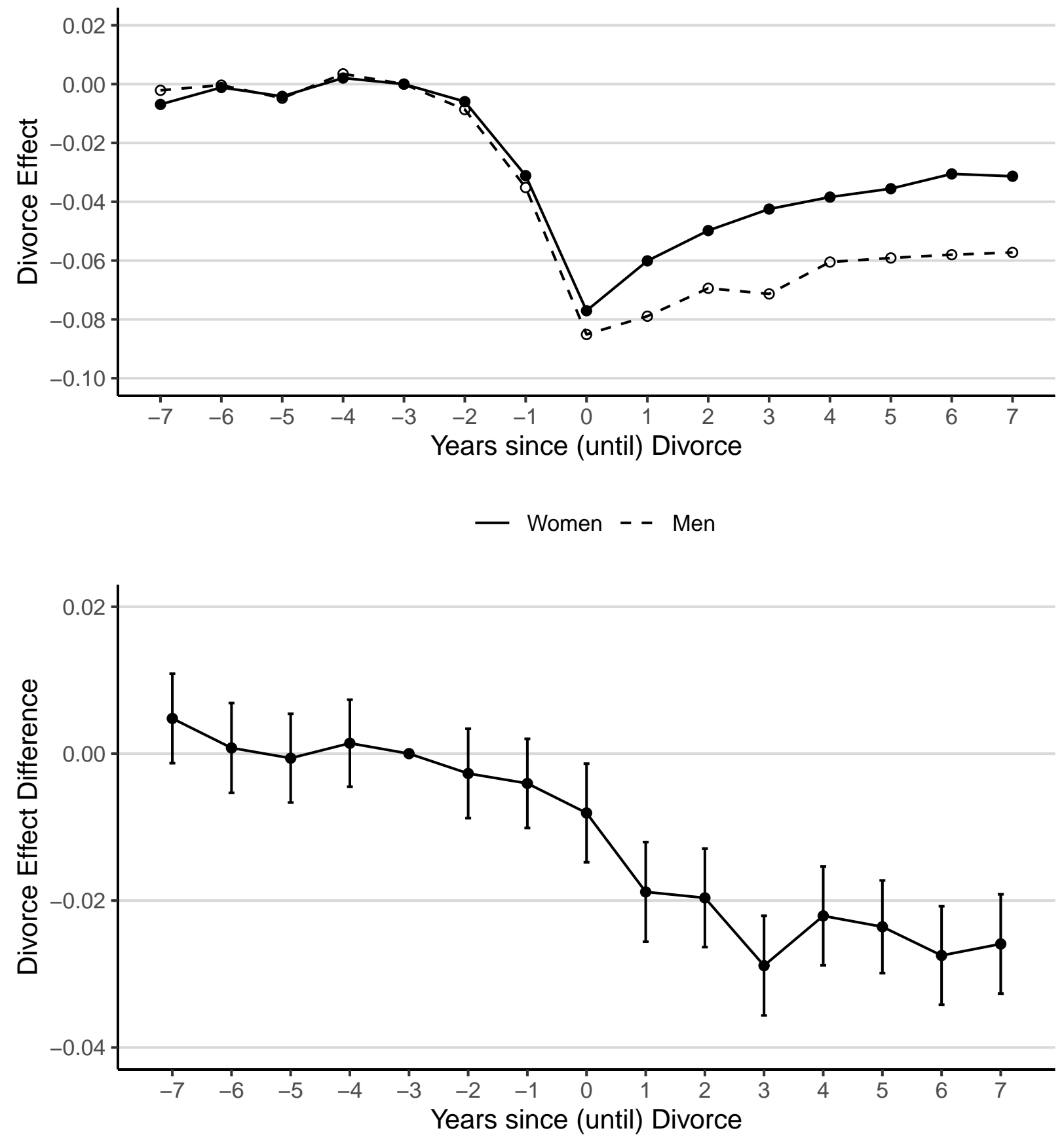

Figure 3: Divorce Effect on Turnout

As can be seen, the gender gap in turnout begins to materialize a couple of years before the divorce and then the gap gradually grows until three years after the divorce when it stabilizes 
around 2.5 percentage points. The gender differences in the divorce effect are statistically significant at the $5 \%$ level from year 0 and onwards (see Table A.1 in the supplementary Appendix for complete results).

\section{Why is the Divorce Effect Gendered?}

The previous findings provide clear evidence that going through a divorce negatively affects voter turnout, and that this effect is particularly pronounced for men. However, so far our analyses do not tell us anything about why this is the case. In this section, we attempt to remedy this by investigating various potential causal mechanisms.

In the section on theory and previous research, we discussed two main reasons why a divorce should affect voter turnout, and why that effect may differ between women and men. A first possibility is that the divorce effect is driven by changes in the socio-economic status and residential mobility. Going through a divorce is typically associated with a decline in the socio-economic position of an individual and a higher probability of residential mobility, two factors that previous research suggest are associated with lower voter turnout 11

In a supplementary analysis, we show that experiencing a divorce has large negative economic consequences for both sexes, although they are particularly marked for women (see Figure A.1). For women, the average family disposable income drops by 40-50 percent, and the probability of receiving means-tested public transfers, such as social or housing

\footnotetext{
${ }^{11}$ See, respectively, Rosenstone $(\overline{1982})$ and Squire et al. (1987) on the impact of economic adversity and residential mobility on voter turnout.
} 
allowance, more than doubles when going through a divorce. We observe similar but smaller effects for men. With respect to residential mobility, the probability of moving almost triples for both sexes as a result of the divorce (see Figure A.2).

The key question here, however, is to what extent do the changes in socio-economic status (SES) and residential mobility help to account for the divorce effect on voter turnout. One way to examine this is by performing a mediation analysis in which we add controls for socio-economic status and residential mobility to our baseline regression model, and observe how much the divorce effect changes in response (Baron and Kenny, 1986).

Figure 4 displays the results from such an analysis. For reasons of comparison, the left part of the figure reproduces the results for the model without controls for potential mechanisms, whereas the rightmost part shows the divorce effects once the effects of socioeconomic position and residential mobility are taken into consideration. More precisely, we include controls for household disposable income, number of children living in the household, two binary indicators recording whether a household has received housing or social allowance during a particular year, and two variables indicating whether an individual has moved either within or between municipalities in a given year.

By comparing the two graphs in Figure 4, we can see that the drop in voter turnout associated with the divorce becomes somewhat less pronounced once we control for socio-economic position and residential mobility. In the baseline model, the divorce reduces turnout by about 7.5 percentage points for women and 8.5 percentage points for men, whereas the corresponding figure in the model with mechanism controls is about 6 percentage points for both sexes. 

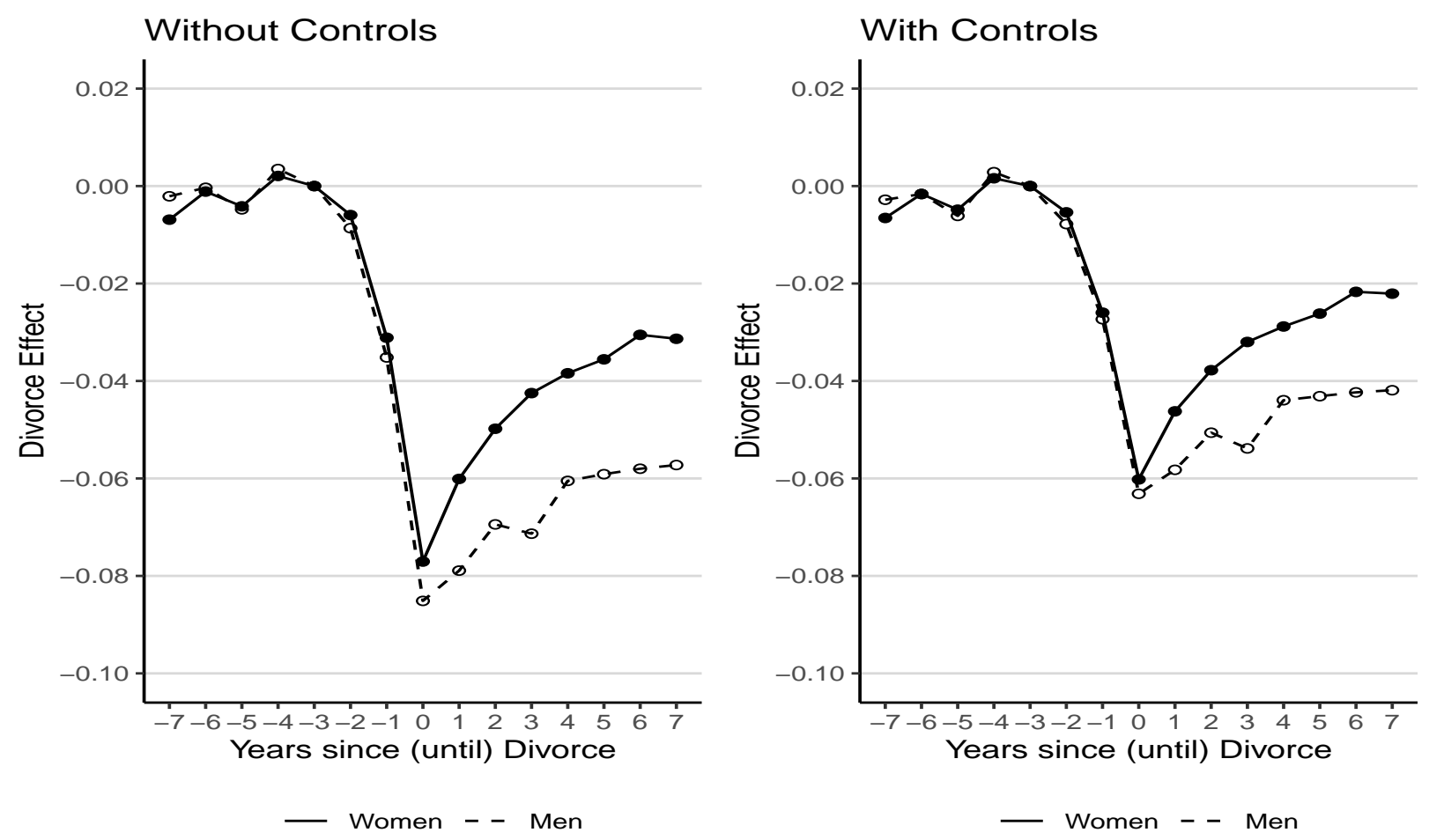

Figure 4: A Baron-Kenny Mediation Analysis

To judge from these results, the impact of the divorce on SES and residential mobility can thus account for about one quarter of the overall effect of divorce on turnout.

However, it is important to note that the gender gap that develops after the divorce effect looks fairly similar in the two graphs. This suggests that changes in SES and residential mobility are not very helpful in explaining why turnout develops differently for women and men following a divorce.

Next, we turn our focus to the impact of spousal political mobilization, which was the second potential mechanism highlighted in the theoretical section. To recap the discussion, the main idea is that since voting is often a joint household activity (e.g., Bhatti et al., 2020, Glaser, 1959), more politically active individuals should mobilize their less politically active 
partners. In a context such as the Swedish one, where voter turnout is higher among women than men, this could potentially help explain why men's turnout is more negatively affected by a divorce. It is equally important to note that this line of reasoning also implies that men's voter turnout should increase more when a couple is formed.

Unfortunately, we cannot observe how the turnout levels of women and men are affected by initial family formation as the household indicator at our disposal only identifies couples who are either married or cohabiting with joint children, whereas cohabiting couples without children are treated as separate households in the data. As a second best, we therefore decided to examine how turnout varies with the time since (until) marriage for the individuals in our sample. To do this, we utilize additional data on turnout from the general elections in 1970 and 1982.12 The results are presented in Figure 5.

Despite the fact that it is common for Swedish couples to cohabit for some time before getting married, we observe a clear effect of marriage on the turnout of men. Turnout develops very similar for both sexes until 1-2 years before the marriage when men's turnout suddenly starts to increase at a faster rate. If we compare post- and pre-marriage turnout, we see that this difference is about 1.5 percentage points larger for men than it is for women.

It is interesting to note that the pattern shown in Figure 5 is a mirror image of the effects of martial disruptions presented earlier. Just as men's turnout is more negatively affected by a divorce, it is also more positively affected by marriage, which is in line with the expectations of the spousal mobilization hypothesis. Thus, before getting married, turnout is ${ }^{12}$ The data for the election in 1982 were collected, and generously shared with us, by Magnus Carlsson and Dan-Olof Rooth. 


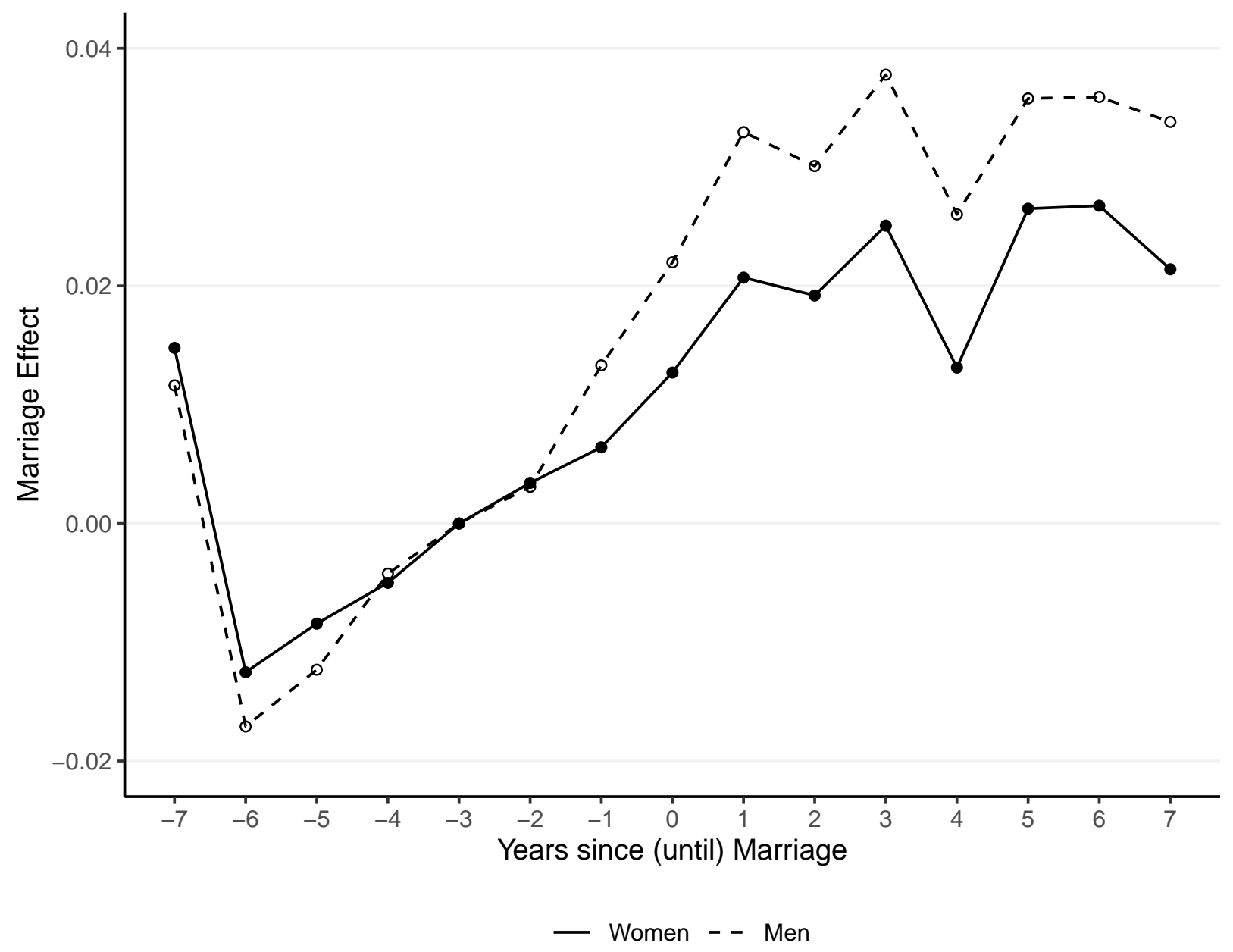

Figure 5: Turnout Effect by time since Marriage

usually somewhat lower for men than for women; however, once they marry, men's turnout converges to that of women's. One likely reason for this is that having a voting spouse tends to mobilize some individuals who had otherwise abstained from voting, and because the baseline probability of voting is lower for men, husbands are more likely to become mobilized by their wives than vice versa. However, when a marriage is dissolved, this spousal mobilization effect disappears, which then becomes particularly detrimental for the voter turnout of men. 
An alternative means to examine the validity of the spousal mobilization mechanism is to study how the divorce effects vary with spousals' pre-marriage turnout. To do this, we first classify the pre-marriage turnout of husbands and wifes as either high - if they voted in all pre-marriage elections for which we have data - or low-if they abstained from voting in at least one election as unmarried. We then estimate our baseline model for each unique combination of spousal pre-marriage turnout. The results are presented in Figure 6 .

The key thing to note is that the gender gap in the divorce effect is reversed as we go from the upper-right to the lower-left of the graph. Hence, in couples where the wife was more likely to vote as unmarried, the negative effect of divorce is more pronounced for men. However, in couples where it was the husband who had the higher pre-marriage turnout, we instead observe a larger effect of divorce on the wife. For couples where both spouses voted as unmarried (the upper-left part of the graph), the results mimic those of our main analysis; moreover, in the small group of couples where both spouses had low pre-marriage turnout (the lower-right part of the graph), the gender difference is rather small and noisy. ${ }^{13}$

These results thus serve to further probe the importance of the spousal mobilization mechanism in understanding the gendered impact of divorces on voter turnout. Thus, judging by these results, being in a marriage will have a larger impact on the turnout of the spouse with the lower baseline probability of voting, which is nowadays typically the husband. However, in contexts where men vote to a higher extent than women we could expect the opposite relationship to appear.

\footnotetext{
${ }^{13}$ In the Supplementary Appendix we show that we obtain a similar pattern of results when splitting the sample by the voting activity of the parents of the spouses (see Table A.7).
} 

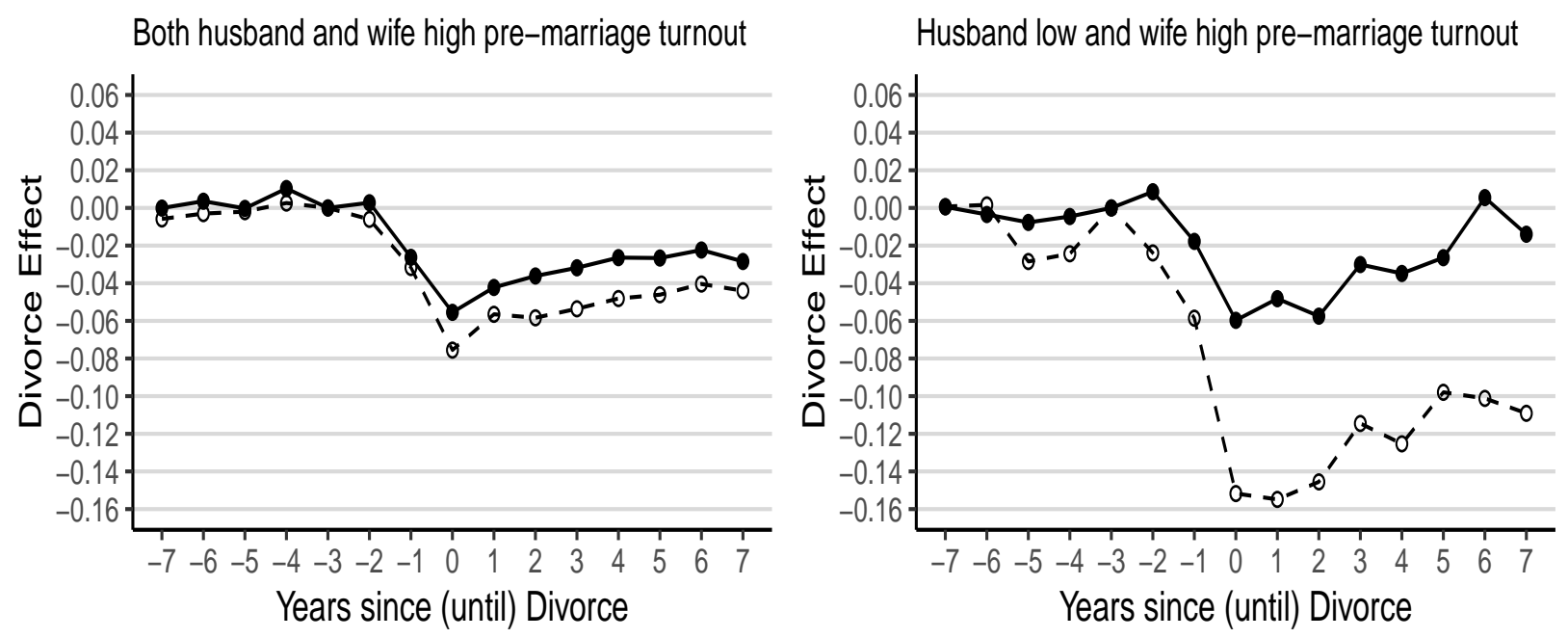

Husband high and wife low pre-marriage turnout

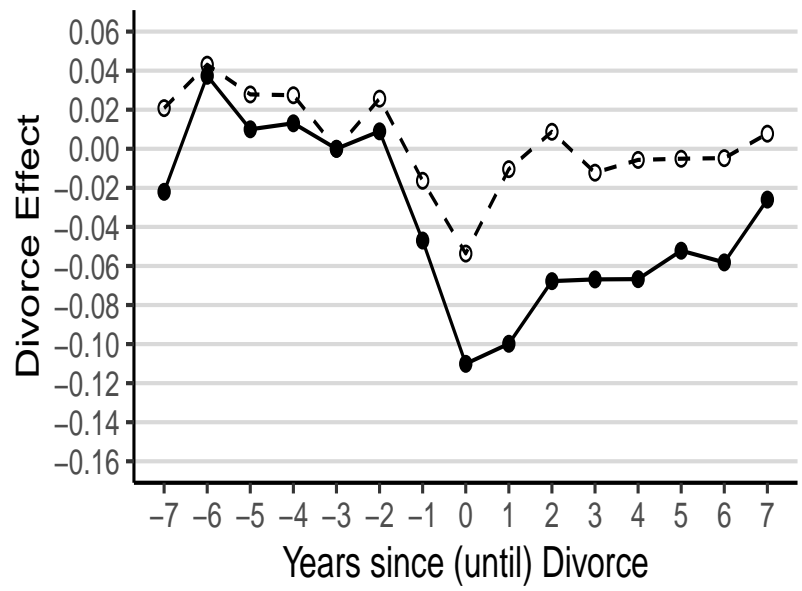

Both husband and wife low pre-marriage turnout

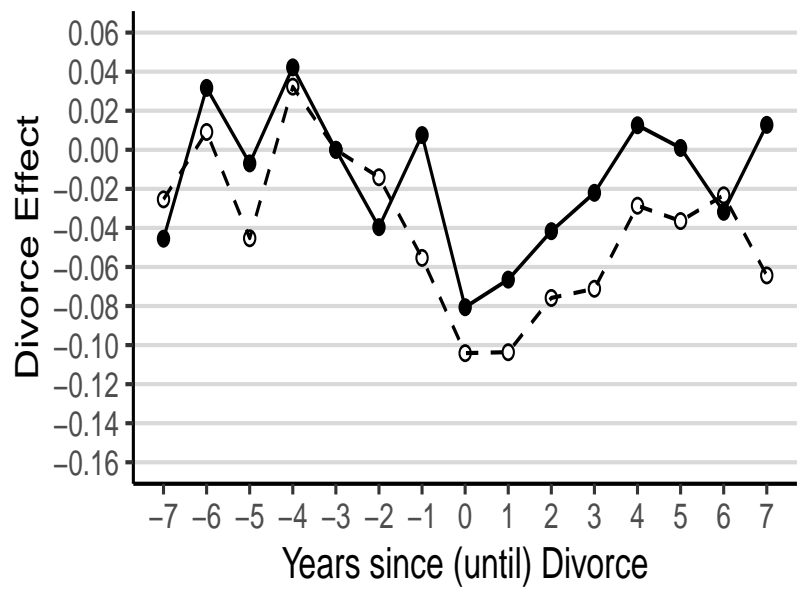

- Women - - Men

Figure 6: Divorce Effect by Pre-Marriage Turnout

In the Supplementary Appendix, we report the results from a number of different sensitivity analyses designed to check the robustness of our main findings. First, we show that the results are robust to the procedure used to adjust for age and election year effects. We obtain very similar results when we drop the expected turnout control from the specification and instead include different combinations of couple, age, and election year fixed effects in 
the model (see Figure A.3. Second, because there is some uncertainty involved in identifying the couples in our data, we have re-estimated our main model replacing the couple fixed effects with individual fixed effects. However, this change hardly affects the results at all (Figure A.4). Another feature of our data that could potentially impact the results is the fact that we are not able to observe all individuals in all three elections. Nonetheless, in the Appendix, we show that we obtain very similar results when restricting attention to the subset of couples for which we can observe the turnout behavior of both spouses in all elections (Figure A.5). Finally, we have checked how the results are affected if we replace the linear probability model with a fixed effects logit model. Despite the fact that the sample size is reduced by two-thirds when using the logit model-because it requires that there is within couple variation in voter turnout - the marginal effects of the logit model closely resembles those of the linear probability model (Figure A.6).

\section{Conclusions}

Political scientists have a long history of being interested in the institution of marriage and its impact on political participation. While there are numerous studies examining the impact of marital or family status on voter turnout, they are mostly based on static comparisons between the married and other categories. Moreover, while researchers are cognizant of the heterogeneous effects of family status on a range of other social outcomes, gendered analyses of the effect of divorce on voting have been exceedingly rare. We follow recent work in employing a dynamic approach, and study the gendered impact of marital disruption, in 
the form of divorce, on turnout. According to our analysis, which draws on high-resolution population-wide Swedish registry data, both sexes are strongly and adversely affected by divorce, but the effect is much more pronounced for men. Consistent with an argument that emphasizes spousal mobilization, we find that this effect is mainly driven by individuals who 'marry up', and since more men than women 'marry up', the woman in a relationship will more often than not be the mobilizing agent 14 We also show that marriage has the opposite effect of divorce and boosts the turnout of men more than that of women, a result which also strongly supports our theoretical interpretation.

How generalizable are our findings? On the one hand, Sweden exemplifies broader trend towards higher turnout among women than men in Western democracies. Men, to a greater extent than women, 'marry up' when it comes to electoral participation. This, in turn, suggests that in many countries, the mechanism of spousal mobilization should work the same way as it does in Sweden: Divorce has a greater negative effect on men, while the opposite is true for the effect of marriage. At the same time, one has to be cautious. Research has shown that while women's economic standard of living declines more than that of men's in the wake of divorce in all countries, this discrepancy is less pronounced in countries with more generous welfare state arrangements, such as Sweden (De Vaus et al., ${ }^{14}$ One alternative interpretation of our finding would be that women would have a stronger post-divorce interest in politics (e.g., child care policies) because of the need to combine work with being the primary caregiver (cf. Iversen and Rosenbluth, 2006). This interpretation does not fit with some of our other findings, however. Notably, this mechanism cannot explain why men see greater increase in turnout than women when marrying. 
2017). Therefore, the socio-economic mechanism by which divorce can affect turnout may be stronger in some other countries. This might in turn result in the between-gender difference in the impact of divorce on turnout being considerably smaller than what we have found in our study.

On the whole, our results underscore the importance of spousal mobilization as a driver of the waxing and waning of political engagement that has been observed in conjunction with changes in marital and family status. Interestingly, the mobilizing agent in a heterosexual couple was historically assumed to be the man. This is evident in the conclusions to Glaser's (1959, p. 570) pioneering work on family ties and voter turnout, where he writes that "if party workers or civic organizations want the greatest return on the use of their scarce services, they should make contact with the most politicized member of a household (usually the husband [emphasis added]) and motivate that member to bring all the other members to the polls." In other words, he suggests that canvassers focus on the male in the household. Since then, however, we have witnessed a reversal of the turnout gap in many democratic countries, suggesting that in those cases it may now be time to turn this advice on its head.

Lastly, recent research has pointed to the reversal of another gender gap. While men used to have more education than women, the opposite is now true in most advanced democracies (Goldin et al., 2006; Van Bavel et al.,2018). This development has led to profound changes in family formation, divorce risk, and within-family relations (Bertrand et al., 2015; Van Bavel et al., 2018). At the same time, if women enjoy higher levels of education, they may also become more likely to exercise political voice, as well as to mobilize others to do the same. 
We argue that these broad societal trends call for further research on the nexus between gender, education, the family, and political engagement.

\section{References}

Abrams, Samuel, Torben Iversen, and David Soskice (2011). "Informal social networks and rational voting". In: British Journal of Political Science, pp. 229-257.

Baron, Reuben M. and David A. Kenny (1986). "The moderator-mediator variable distinction in social psychological research: Conceptual, strategic, and statistical considerations." In: Journal of personality and social psychology 51.6, p. 1173.

Bellettini, Giorgio, Carlotta Berti Ceroni, Enrico Cantoni, Chiara Monfardini, and Jerome Schafer (2020). Family Norms and the Gender Turnout Gap. English. Working Paper 2020.

Bersani, Bianca E, John H Laub, and Paul Nieuwbeerta (2009). "Marriage and desistance from crime in the Netherlands: Do gender and socio-historical context matter?" In: Journal of Quantitative Criminology 25.1, pp. 3-24.

Bertrand, Marianne, Emir Kamenica, and Jessica Pan (2015). "Gender identity and relative income within households". In: The Quarterly Journal of Economics 130.2, pp. 571-614.

Bhatti, Yosef, Edward Fieldhouse, and Kasper M Hansen (2020). "It'sa Group thing: How voters go to the polls together". In: Political Behavior 42.1, pp. 1-34. 
Bianchi, Suzanne M, Lekha Subaiya, and Joan R Kahn (1999). "The gender gap in the economic well-being of nonresident fathers and custodial mothers". In: Demography 36.2, pp. 195-203.

Bird, Karen, Thomas Saalfeld, and Andreas M Wüst (2011). "Voter turnout among immigrants and visible minorities in comparative perspective". In: The Political Representation of Immigrants and Minorities: Voters, Parties, and Parliaments in Liberal Democracies, pp. 51-76.

Blais, André, Carol Galais, and Maxime Coulombe (2019). "The effect of social pressure from family and friends on turnout". In: Journal of Social and Personal Relationships 36.9, pp. $2824-2841$.

Carreras, Miguel (2018). "Why no gender gap in electoral participation? A civic duty explanation". In: Electoral Studies 52, pp. 36-45.

Cascio, Elizabeth U and Na'ama Shenhav (2020). "A Century of the American Woman Voter: Sex Gaps in Political Participation, Preferences, and Partisanship Since Women's Enfranchisement". In: Journal of Economic Perspectives 34.2, pp. 24-48.

Coffé, Hilde and Catherine Bolzendahl (2010). "Same game, different rules? Gender differences in political participation". In: Sex roles 62.5-6, pp. 318-333.

Cutts, David and Edward Fieldhouse (2009). "What small spatial scales are relevant as electoral contexts for individual voters? The importance of the household on turnout at the 2001 general election". In: American Journal of Political Science 53.3, pp. 726-739. 
De Vaus, David, Matthew Gray, Lixia Qu, and David Stanton (2017). "The economic consequences of divorce in six OECD countries". In: Australian Journal of Social Issues 52.2, pp. 180-199.

Foos, Florian and Eline A De Rooij (2017). "All in the family: Partisan disagreement and electoral mobilization in intimate networks-A spillover experiment". In: American Journal of Political Science 61.2, pp. 289-304.

Franklin, Mark N (2004). Voter turnout and the dynamics of electoral competition in established democracies since 1945. Cambridge University Press.

Frödin Gruneau, Moa (2018). "Reconsidering the partner effect on voting". In: Electoral Studies 53, pp. 48-56.

Frödin Gruneau, Moa (2020). "Assortative mating and turnout: a self-reinforcing pattern of unequal voting participation". In: European Political Science Review 12.2, pp. 155-171.

Gallego, Aina and Daniel Oberski (2012). "Personality and political participation: The mediation hypothesis". In: Political behavior 34.3, pp. 425-451.

Glaser, William A (1959). "The family and voting turnout". In: Public Opinion Quarterly 23.4, pp. 563-570.

Goldin, Claudia, Lawrence F Katz, and Ilyana Kuziemko (2006). "The homecoming of American college women: The reversal of the college gender gap". In: Journal of Economic perspectives 20.4, pp. 133-156.

Highton, Benjamin and Raymond E Wolfinger (2001). "The first seven years of the political life cycle". In: American Journal of Political Science, pp. 202-209. 
Hobbs, William R, Nicholas A Christakis, and James H Fowler (2014). "Widowhood effects in voter participation". In: American Journal of Political Science 58.1, pp. 1-16.

Iversen, Torben and Frances Rosenbluth (2006). "The political economy of gender: Explaining cross-national variation in the gender division of labor and the gender voting gap". In: American Journal of Political Science 50.1, pp. 1-19.

Kern, Holger Lutz (2010). "The political consequences of transitions out of marriage in Great Britain". en. In: Electoral Studies 29.2, pp. 249-258.

King, Ryan D, Michael Massoglia, and Ross MacMillan (2007). "The context of marriage and crime: Gender, the propensity to marry, and offending in early adulthood". In: Criminology 45.1, pp. 33-65.

Leighley, Jan E and Jonathan Nagler (2013). Who votes now?: Demographics, issues, inequality, and turnout in the United States. Princeton University Press.

Leopold, Thomas (2018). "Gender differences in the consequences of divorce: A study of multiple outcomes". In: Demography 55.3, pp. 769-797.

Lindgren, Karl-Oskar, Sven Oskarsson, and Mikael Persson (2019). "Enhancing Electoral Equality: Can Education Compensate for Family Background Differences in Voting Participation?" en. In: American Political Science Review 113.1, pp. 108-122.

Mulder, Clara H and Michael Wagner (2010). "Union dissolution and mobility: Who moves from the family home after separation?" In: Journal of Marriage and Family 72.5, pp. 12631273. 
Nickerson, David W (2008). "Is voting contagious? Evidence from two field experiments". In: American Political Science Review, pp. 49-57.

Pacheco, Julianna Sandell and Eric Plutzer (2007). "Stay in school, don't become a parent: Teen life transitions and cumulative disadvantages for voter turnout". In: American Politics Research 35.1, pp. 32-56.

Plutzer, Eric (2002). "Becoming a habitual voter: Inertia, resources, and growth in young adulthood". In: American Political Science Review 96.1, pp. 41-56.

Plutzer, Eric and Nancy Wiefek (2006). "Family transitions, economic status, and voter turnout among African-American inner-city women". In: Social Science Quarterly 87.3, pp. $658-678$.

Rosenstone, Steven J (1982). "Economic adversity and voter turnout". In: American Journal of Political Science, pp. 25-46.

Schmitt, David P, Anu Realo, Martin Voracek, and Jüri Allik (2008). "Why can’t a man be more like a woman? Sex differences in Big Five personality traits across 55 cultures." In: Journal of personality and social psychology 94.1, p. 168.

Shore, Jennifer (2020). "Singled Out or Drawn In? Social polices and lone mothers' political engagement". In: Politics $\&$ Gender 16.2, pp. 471-497.

Smock, Pamela J, Wendy D Manning, and Sanjiv Gupta (1999). "The effect of marriage and divorce on women's economic well-being". In: American Sociological Review, pp. 794-812. Squire, Peverill, Raymond E Wolfinger, and David P Glass (1987). "Residential mobility and voter turnout". In: American Political Science Review, pp. 45-65. 
Stanfors, Maria, Fredrik N G Andersson, and Glenn Sandström (2020). A Century of Divorce: Long-Term Socioeconomic Restructuring and the Divorce Rate in Sweden, 1915-2010. English. WorkingPaper 2020:2. Series: Lund Papers in Economic Demography (LPED). Statistics Sweden (2012). Svenskt valdeltagande under hundra år. Swedish. OCLC: 939798165. Stockholm: Statistiska centralbyrån.

Stoker, Laura and M Kent Jennings (1995). "Life-cycle transitions and political participation: The case of marriage". In: American Political Science Review 89.2, pp. 421-433.

Strate, John M, Charles J Parrish, Charles D Elder, and Coit Ford (1989). "Life span civic development and voting participation". In: American Political Science Review 83.2, pp. 443464.

Timpone, Richard J (1998). "Structure, behavior, and voter turnout in the United States". In: American Political Science Review 92.1, pp. 145-158.

Umberson, Debra (1987). "Family status and health behaviors: Social control as a dimension of social integration". In: Journal of health and social behavior, pp. 306-319.

Van Bavel, Jan, Christine R Schwartz, and Albert Esteve (2018). "The reversal of the gender gap in education and its consequences for family life". In: Annual Review of Sociology 44, pp. 341-360.

Verba, Sidney, Kay Lehman Schlozman, and Henry E Brady (1995). Voice and equality: Civic voluntarism in American politics. Harvard University Press. 
Voorpostel, Marieke and Hilde Coffé (2012). "Transitions in partnership and parental status, gender, and political and civic participation". In: European Sociological Review 28.1, pp. 28-42.

Weitzman, Lenore J (1985). The divorce revolution: The unexpected social and economic consequences for women and children in America. New York: The Free Press.

Wolfinger, Nicholas H. and Raymond E. Wolfinger (2008). "Family structure and voter turnout". In: Social Forces 86.4, pp. 1513-1528.

Wolfinger, Raymond E and Steven J Rosenstone (1980). Who votes? Vol. 22. Yale University Press. 
Online Appendix of "The Ex-Factor: Examining the Gendered Effect of Divorce on Voter Turnout" 


\section{Details on data and measures}

This section provides a description of the data availability, data sources and the main variables used in this study.

\section{Data availability and replication}

We use individual level data from Swedish registers. The data material is located on an encrypted server to which we have to log in through a remote desktop application in order to perform all of our data analyses. Due to the extreme sensitivity of the data, we are under contractual and ethical obligation not to distribute these data to others.

For those researchers who want to replicate our results there are two ways to get access to the administrative data. The first way is to order the data directly from Statistics Sweden (SCB). Statistics Sweden presently requires that researchers obtain a permission from a Swedish Ethical Review Board before data can be ordered (a description, in Swedish, of how to order data from Statistics Sweden is available at: https://www.scb.se/en/services/ guidance-for-researchers-and-universities/). We will also make available a complete list all of the variables that we ordered from Statistics Sweden for this project, together with our computer scripts.

The second way to replicate our analyses is to come to Sweden and reanalyze these data through the same remote server system that we used. Researchers interested in using this option should reach out to us prior to coming to Sweden so that we can apply for approval from the Ethical Review Board for the researcher to temporarily be added to our research team, which is mandatory in order to get access to the remote server system.

\section{Variables and data sources}

Turnout - Individual level turnout information from five elections - the national elections in 1970, 1982, 1994, 2010 and 2018. The information on the first four elections is retrieved from scanned electoral rolls and is currently stored at Statistics Sweden. The data for the 1982 election were collected, and generously shared with us, by Magnus Carlsson and DanOlof Rooth. The data from the 1970, 1994, and 2010 election were collected by Karl-Oskar Lindgren and Sven Oskarsson and the data-collecting prcedure is decsribed in Lindgren et al. (2019). As from the general election in 2018 Statistics Sweden collects population-wide 
turnout data as part of the official statistics.

Female - Equal to 1 if female. Information is retrieved from the Swedish Population Register.

Birth Year - Information is retrieved from the Swedish Population Register.

Start Marriage — Start-date of marriage. Information is retrieved from the Swedish Population Register.

End Marriage - End-date of marriage. Information is retrieved from the Swedish Population Register.

Household ID - Two divorced individuals are defined as having belonged to the same household if they have the same start- and end-rates of their marriages. In the few cases in which several couples have the same start- and end-dates of their marriages we also use information on place of residence (geographical grids based on annual information on exact coordinates of the house in which the individuals live) to discriminate between different households. Information on the geographical grids is retrieved from the Real Estate Property Register.

Years of Education Educational attainment at the time of the election according to the three-digit Swedish standard classification of education (SUN 2000). Following the manual for classifying educational programmes in OECD countries (ISCED-97), we assigned the following years of schooling to each category: (old) primary school (7); (new) compulsory school (9); (old) junior secondary education (9.5); high school (10-12 depending on the program); short university (13); longer university (14-16 depending on the program); short postgraduate (17); long post-graduate (19). The information on educational attainment is retrieved from the 1991-2010 waves of the Longitudinal integration database for health insurance and labour market studies (LISA by Swedish acronym)

Immigrant Background - Equal to 1 if the individual or at least one of his/her parents are born abroad; equal to 0 if the individual is born in Sweden by two Sweden-born parents. The information retrieved from the Swedish Population Register.

Family Income - The sum of individual disposable income (DispInk) for all individuals belonging to the same household. To increase comparison over time, income is expressed in 2010 prices. The information is retrieved from Longitudinal integration database for health 
insurance and labour market studies (LISA by Swedish acronym).

Number of Children - The number of children aged 0-17 living in the household. The information is retrieved from Longitudinal integration database for health insurance and labour market studies (LISA by Swedish acronym).

Social Allowance - Equal to 1 if the individual receives social allowance. The information is retrieved from Longitudinal integration database for health insurance and labour market studies (LISA by Swedish acronym).

Social Allowance - Equal to 1 if the individual receives housing allowance. The information is retrieved from Longitudinal integration database for health insurance and labour market studies (LISA by Swedish acronym).

Municipality of residence - Code for the municipality. The information retrieved from the Swedish Population Register.

\section{Supplementary Analyses}

In this section we provide some details on the auxiliary results and robustness checks briefly discussed in the main text.

\section{Main Results in Table Format}

For reasons of completeness Table A.1 displays the regression coefficients used to construct the Figures displayed in the main text. The column headings indicate the name of the figure corresponding to the different results.

Table A.1: Main Results in Table Format

\begin{tabular}{lcccccc}
\hline & Fig. 3 & Fig. 4b & Fig. 6a & Fig. 6b & Fig. 6c & Fig. 6d \\
\hline Year (-8) & -0.003 & -0.005 & 0.002 & -0.015 & 0.022 & -0.007 \\
& $(0.003)$ & $(0.003)$ & $(0.004)$ & $(0.017)$ & $(0.019)$ & $(0.034)$ \\
Year (-7) & -0.007 & -0.007 & 0.000 & 0.001 & -0.022 & -0.046 \\
& $(0.004)$ & $(0.004)$ & $(0.005)$ & $(0.022)$ & $(0.027)$ & $(0.047)$ \\
\hline
\end{tabular}

Continued on next page 
Table A.1: Main Results in Table Format

\begin{tabular}{|c|c|c|c|c|c|c|}
\hline & Fig. 3 & Fig. $4 \mathrm{~b}$ & Fig. 6a & Fig. $6 \mathrm{~b}$ & Fig. 6c & Fig. 6d \\
\hline \multirow[t]{2}{*}{ Year $(-6)$} & -0.001 & -0.002 & 0.004 & -0.003 & 0.037 & 0.032 \\
\hline & $(0.004)$ & $(0.004)$ & $(0.005)$ & $(0.022)$ & $(0.026)$ & $(0.046)$ \\
\hline \multirow[t]{2}{*}{ Year $(-5)$} & -0.004 & -0.005 & 0.000 & -0.008 & 0.010 & -0.007 \\
\hline & $(0.004)$ & $(0.004)$ & $(0.005)$ & $(0.021)$ & $(0.027)$ & $(0.048)$ \\
\hline \multirow[t]{2}{*}{ Year (-4) } & 0.002 & 0.002 & 0.010 & -0.005 & 0.013 & 0.042 \\
\hline & $(0.003)$ & $(0.003)$ & $(0.005)$ & $(0.022)$ & $(0.025)$ & $(0.041)$ \\
\hline \multirow{2}{*}{ Year (-2) } & -0.006 & -0.005 & 0.003 & 0.009 & 0.009 & -0.040 \\
\hline & $(0.003)$ & $(0.003)$ & $(0.005)$ & $(0.021)$ & $(0.025)$ & $(0.044)$ \\
\hline \multirow[t]{2}{*}{ Year $(-1)$} & -0.031 & -0.026 & -0.026 & -0.018 & -0.047 & 0.008 \\
\hline & $(0.003)$ & $(0.003)$ & $(0.005)$ & $(0.021)$ & $(0.024)$ & $(0.041)$ \\
\hline \multirow[t]{2}{*}{ Year (0) } & -0.077 & -0.060 & -0.055 & -0.060 & -0.110 & -0.081 \\
\hline & $(0.003)$ & $(0.003)$ & $(0.005)$ & $(0.020)$ & $(0.024)$ & $(0.040)$ \\
\hline \multirow[t]{2}{*}{ Year (1) } & -0.060 & -0.046 & -0.042 & -0.048 & -0.100 & -0.066 \\
\hline & $(0.003)$ & $(0.003)$ & $(0.005)$ & $(0.021)$ & $(0.024)$ & $(0.040)$ \\
\hline \multirow[t]{2}{*}{ Year (2) } & -0.050 & -0.038 & -0.036 & -0.057 & -0.068 & -0.042 \\
\hline & $(0.003)$ & $(0.003)$ & $(0.005)$ & $(0.021)$ & $(0.024)$ & $(0.041)$ \\
\hline \multirow[t]{2}{*}{ Year (3) } & -0.042 & -0.032 & -0.032 & -0.030 & -0.067 & -0.022 \\
\hline & $(0.003)$ & $(0.003)$ & $(0.005)$ & $(0.021)$ & $(0.025)$ & $(0.040)$ \\
\hline \multirow[t]{2}{*}{ Year (4) } & -0.038 & -0.029 & -0.026 & -0.035 & -0.067 & 0.013 \\
\hline & $(0.003)$ & $(0.003)$ & $(0.005)$ & $(0.020)$ & $(0.025)$ & $(0.040)$ \\
\hline \multirow[t]{2}{*}{ Year (5) } & -0.036 & -0.026 & -0.027 & -0.026 & -0.052 & 0.001 \\
\hline & $(0.003)$ & $(0.003)$ & $(0.004)$ & $(0.015)$ & $(0.018)$ & $(0.032)$ \\
\hline \multirow[t]{2}{*}{ Year (6) } & -0.031 & -0.022 & -0.022 & 0.005 & -0.058 & -0.032 \\
\hline & $(0.003)$ & $(0.003)$ & $(0.005)$ & $(0.020)$ & $(0.024)$ & $(0.040)$ \\
\hline \multirow[t]{2}{*}{ Year (7) } & -0.031 & -0.022 & -0.028 & -0.014 & -0.026 & 0.013 \\
\hline & $(0.003)$ & $(0.003)$ & $(0.005)$ & $(0.020)$ & $(0.024)$ & $(0.039)$ \\
\hline \multirow[t]{2}{*}{ Year (8) } & -0.024 & -0.016 & -0.017 & 0.012 & -0.006 & 0.084 \\
\hline & $(0.003)$ & $(0.003)$ & $(0.004)$ & $(0.016)$ & $(0.019)$ & $(0.032)$ \\
\hline \multirow[t]{2}{*}{ Male $\times$ Year $(-8)$} & -0.001 & -0.003 & -0.004 & -0.013 & -0.007 & -0.026 \\
\hline & $(0.002)$ & $(0.002)$ & $(0.003)$ & $(0.016)$ & $(0.015)$ & $(0.026)$ \\
\hline Male $\times$ Year $(-7)$ & 0.005 & 0.004 & -0.006 & 0.000 & 0.043 & 0.020 \\
\hline
\end{tabular}

Continued on next page 
Table A.1: Main Results in Table Format

\begin{tabular}{ccccccc}
\hline & Fig. 3 & Fig. 4b & Fig. 6a & Fig. 6b & Fig. 6c & Fig. 6d \\
\hline & $(0.003)$ & $(0.003)$ & $(0.004)$ & $(0.019)$ & $(0.021)$ & $(0.034)$ \\
Male $\times$ Year $(-6)$ & 0.001 & 0.000 & -0.007 & 0.005 & 0.006 & -0.023 \\
& $(0.003)$ & $(0.003)$ & $(0.004)$ & $(0.020)$ & $(0.020)$ & $(0.037)$ \\
Male $\times$ Year $(-5)$ & -0.001 & -0.001 & -0.002 & -0.021 & 0.018 & -0.038 \\
& $(0.003)$ & $(0.003)$ & $(0.004)$ & $(0.021)$ & $(0.020)$ & $(0.037)$ \\
Male $\times$ Year $(-4)$ & 0.001 & 0.001 & -0.008 & -0.020 & 0.014 & -0.010 \\
& $(0.003)$ & $(0.003)$ & $(0.004)$ & $(0.020)$ & $(0.020)$ & $(0.032)$ \\
Male $\times$ Year $(-2)$ & -0.003 & -0.002 & -0.009 & -0.033 & 0.017 & 0.026 \\
& $(0.003)$ & $(0.003)$ & $(0.004)$ & $(0.020)$ & $(0.019)$ & $(0.032)$ \\
Male $\times$ Year $(-1)$ & -0.004 & -0.001 & -0.005 & -0.041 & 0.031 & -0.063 \\
& $(0.003)$ & $(0.003)$ & $(0.004)$ & $(0.020)$ & $(0.020)$ & $(0.032)$ \\
Male $\times$ Year $(0)$ & -0.008 & -0.003 & -0.020 & -0.092 & 0.056 & -0.024 \\
& $(0.003)$ & $(0.003)$ & $(0.005)$ & $(0.021)$ & $(0.022)$ & $(0.037)$ \\
Male $\times$ Year $(1)$ & -0.019 & -0.012 & -0.014 & -0.107 & 0.089 & -0.037 \\
& $(0.003)$ & $(0.004)$ & $(0.005)$ & $(0.022)$ & $(0.022)$ & $(0.037)$ \\
Male $\times$ Year $(2)$ & -0.020 & -0.013 & -0.022 & -0.088 & 0.076 & -0.034 \\
& $(0.003)$ & $(0.003)$ & $(0.005)$ & $(0.021)$ & $(0.021)$ & $(0.037)$ \\
Male $\times$ Year $(3)$ & -0.029 & -0.022 & -0.022 & -0.084 & 0.055 & -0.049 \\
Male $\times$ Year $(8)$ & -0.026 & -0.019 & -0.020 & -0.082 & 0.027 & -0.056 \\
& $(0.002)$ & $(0.002)$ & $(0.003)$ & $(0.015)$ & $(0.014)$ & $(0.024)$ \\
\hline \multirow{3}{*}{ Male $\times$ Year $(5)$} & -0.024 & -0.017 & -0.019 & -0.072 & 0.047 & -0.037 \\
& $(0.003)$ & $(0.003)$ & $(0.005)$ & $(0.020)$ & $(0.020)$ & $(0.036)$ \\
& -0.022 & -0.015 & -0.022 & -0.091 & 0.061 & -0.041 \\
& $(0.003)$ & $(0.003)$ & $(0.005)$ & $(0.022)$ & $(0.022)$ & $(0.035)$ \\
& -0.027 & -0.021 & -0.018 & -0.107 & 0.053 & 0.008 \\
& -0.026 & -0.020 & -0.016 & -0.095 & 0.034 & -0.077 \\
& $(0.003)$ & $(0.003)$ & $(0.005)$ & $(0.022)$ & $(0.023)$ & $(0.037)$ \\
& & & & &
\end{tabular}




\section{Divorce Effects on SES and Mobility}

In the main text we discuss possible mechanisms accounting for why a divorce should affect voter turnout, and why that effect may differ between women and men. One possibility is that the divorce effect is driven by changes in socio-economic status and residential mobility.

In Figures A.1 and A.2 we display estimated divorce effects on different SES measures for women (solid line) and men (dashed line), respectively, based on our main model specification and using the year 3 as our reference category. Figure A.1 shows that family income (measured as disposable income in 100's of SEK expressed in 2010 prices) and number of children in the household decline whereas the probability of receiving social and housing allowance increases for both sexes, but more so for women than for men. Figure A.2 instead suggest that the divorce effect of probability of moving, although large in magnitude, does not differ across men and women. 
Family Income

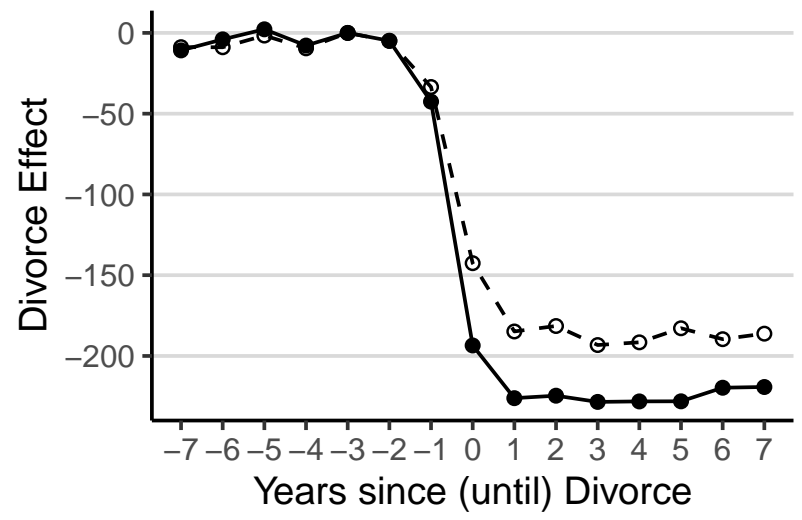

Social Allowance

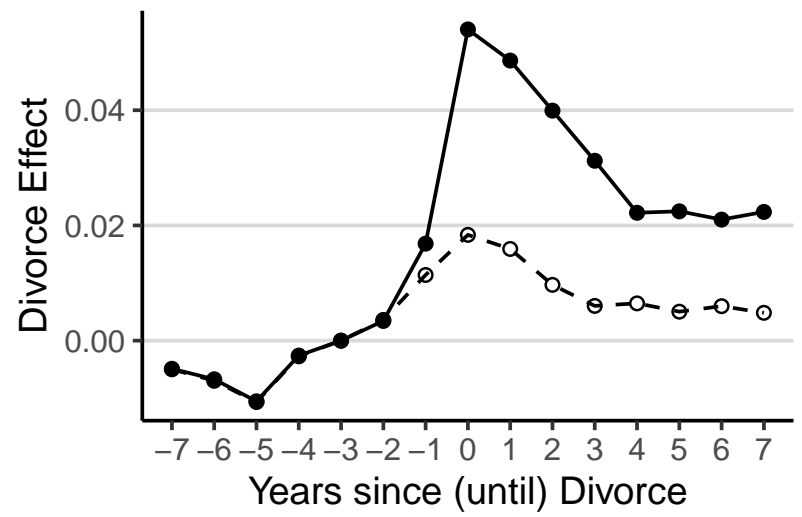

Nr. of Children in Household

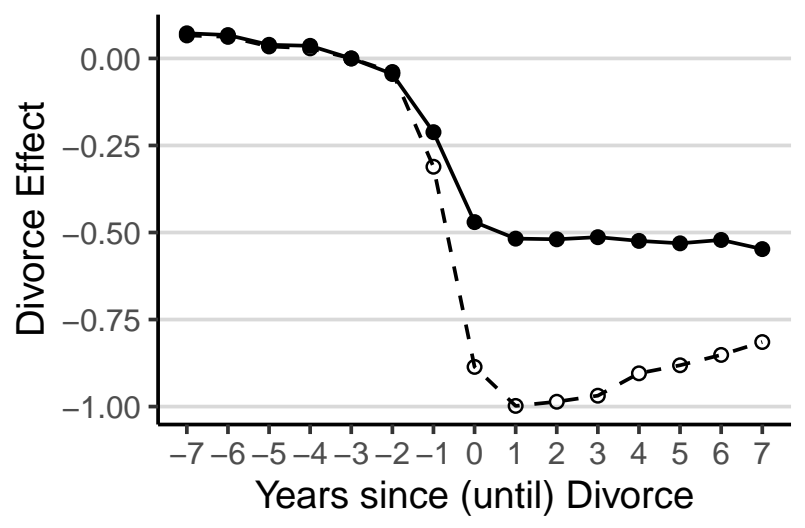

Housing Allowance

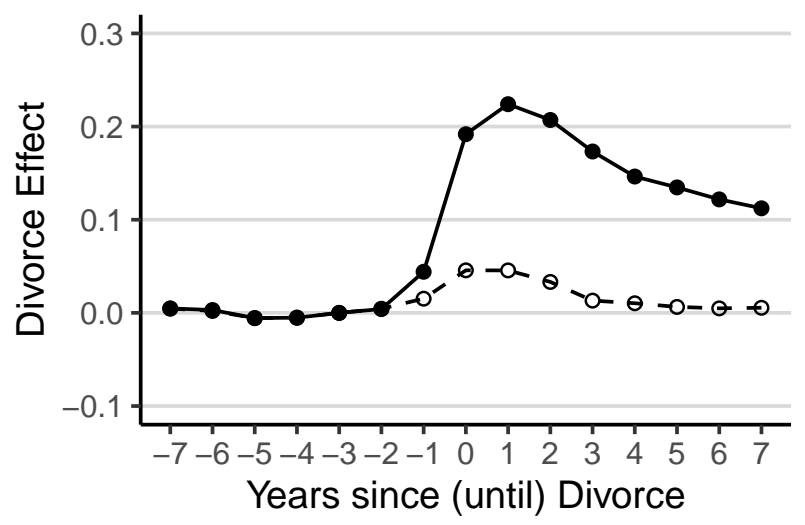

- Women - - Men

Figure A.1: Divorce Impact on SES 

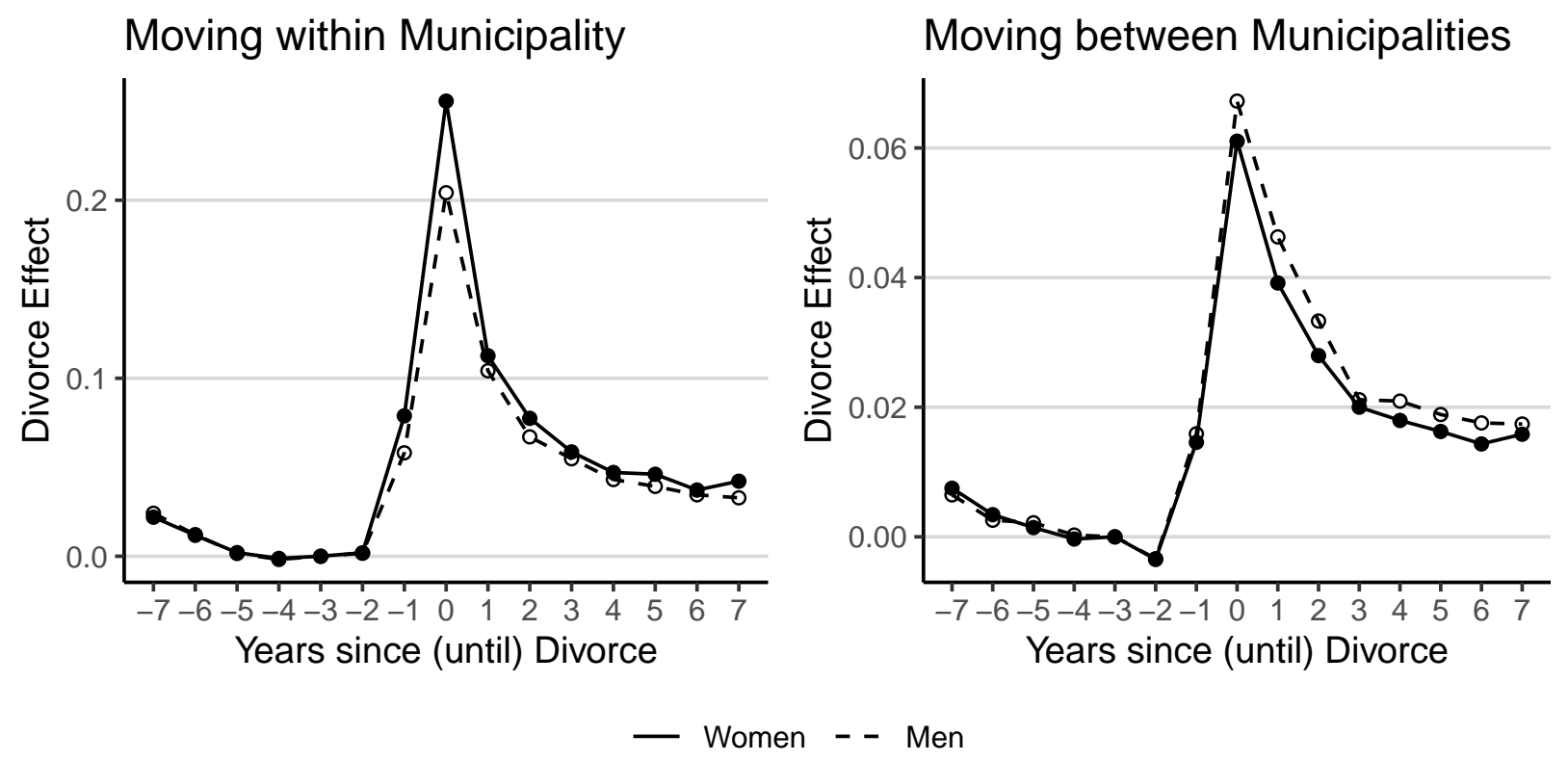

Figure A.2: Divorce Impact on Residential Mobility 


\section{Dropping the Expected Turnout Controls}

In the main text we discuss the fact that we are not able to directly control for age and election year fixed effects due to the inclusion of couple fixed effects in the regression models. To obviate this problem we add a control for average turnout within all unique combinations of birth year, sex, and election year.

In Figure A.3 we show that the pattern of results is very similar when dropping this control from the model specification and instead include different combinations of couple, age and election year fixed effects among the regressors. More specifically, in panel (a) we only include couple fixed effects whereas the results in panel (b) are based on a model controlling for both couple and age fixed effects. In panels (c) and (d) we display corresponding results from models including controls for election year but dropping the couple fixed effects.

\section{Replacing Couple Fixed Effects with Individual Fixed Effects}

As explained in the main text, there is some uncertainty involved in identifying the married couples in our data. Therefore, we have re-estimated our main model replacing the couple fixed effects with individual fixed effects that can be directly observed in our data. As can be seen from the results displayed in Figure A.4 we obtain very similar results when replacing the couple fixed effects with individual fixed effects.

https://www.overleaf.com/project/5cbeef0ddbe81a7734b81f47

\section{Restricting the Sample to Completely Observed Couples}

To be included in the sample used in the main text, it is required that we are able to observe both individuals in a couple in at least one of the three elections for which we have turnout information $(1994,2010$, and 2018) 15 In Figure A.5 we display results based on a sample restricted to couples for which we can observe the turnout behavior of both spouses in all three elections $(N=734,376)$. Despite the ensuing drop in sample size by approximately $50 \%$ the results are very similar to the ones presented in Figure 3 in the main text.

${ }^{15}$ To identify the divorce effect data from at least two elections for each couple is necessary. Couples for which we have complete data from a single election will only contribute to the identification of the effects of the control variables. 
Figure A.3: Alternative Procedures to Deal with Collinearity

(a) Couple FE

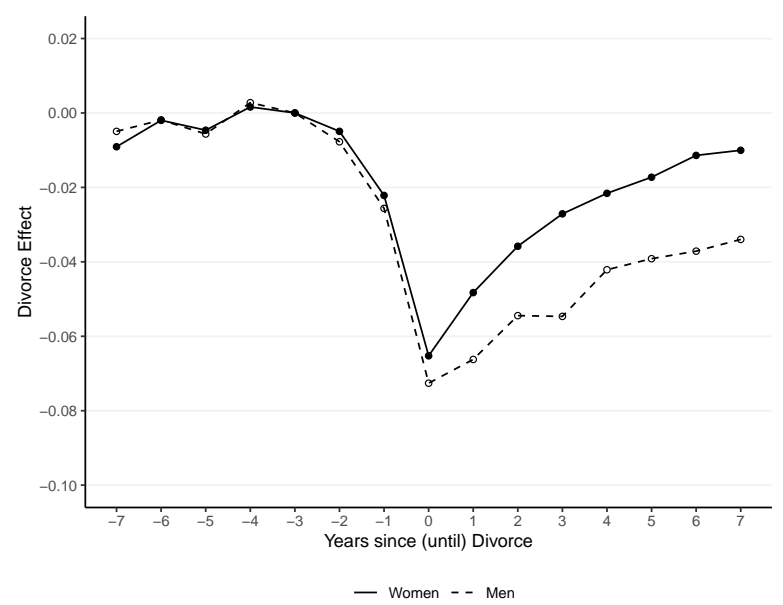

(c) Election Year FE

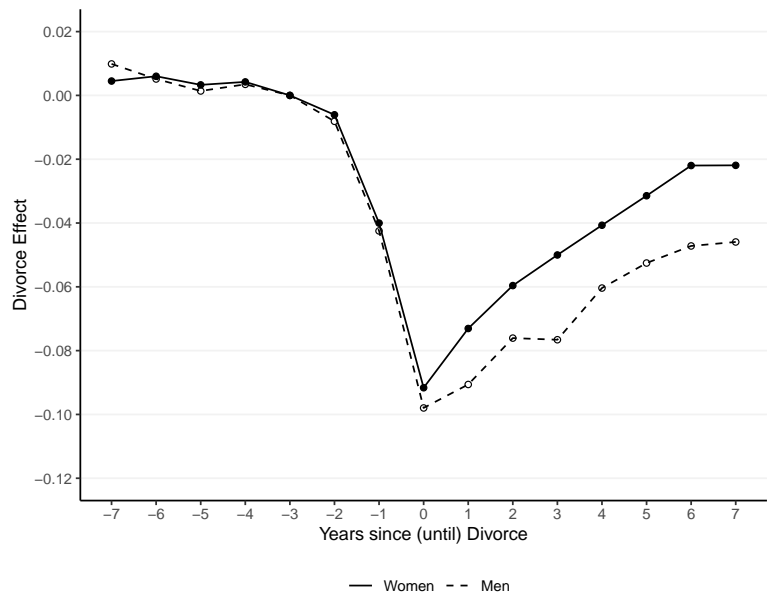

(b) Couple FE + Age FE

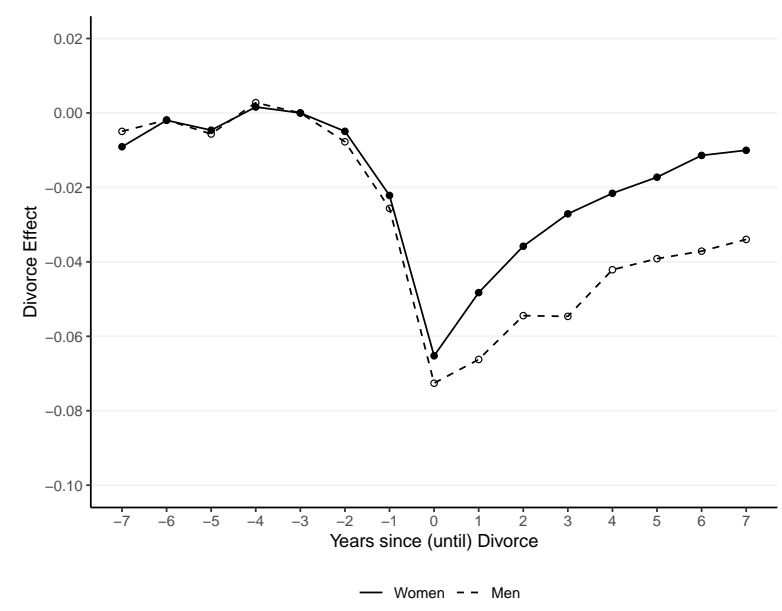

(d) Election Year FE + Age FE

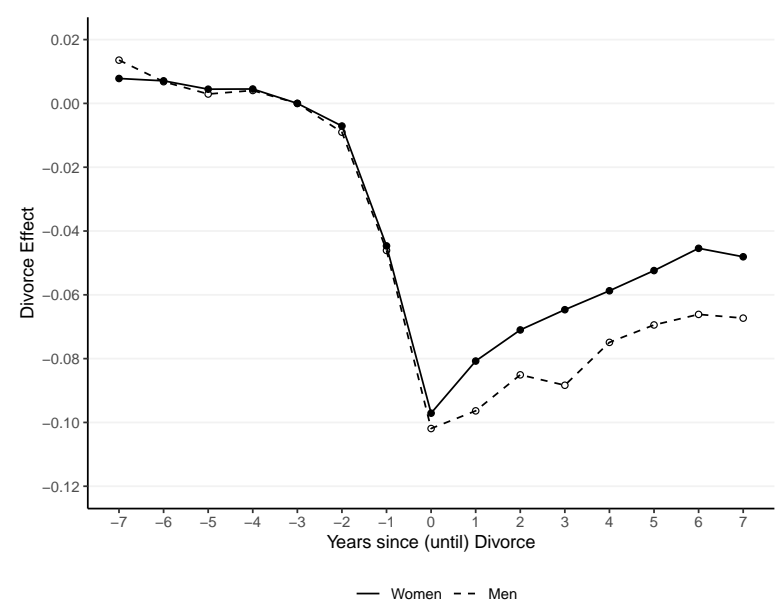




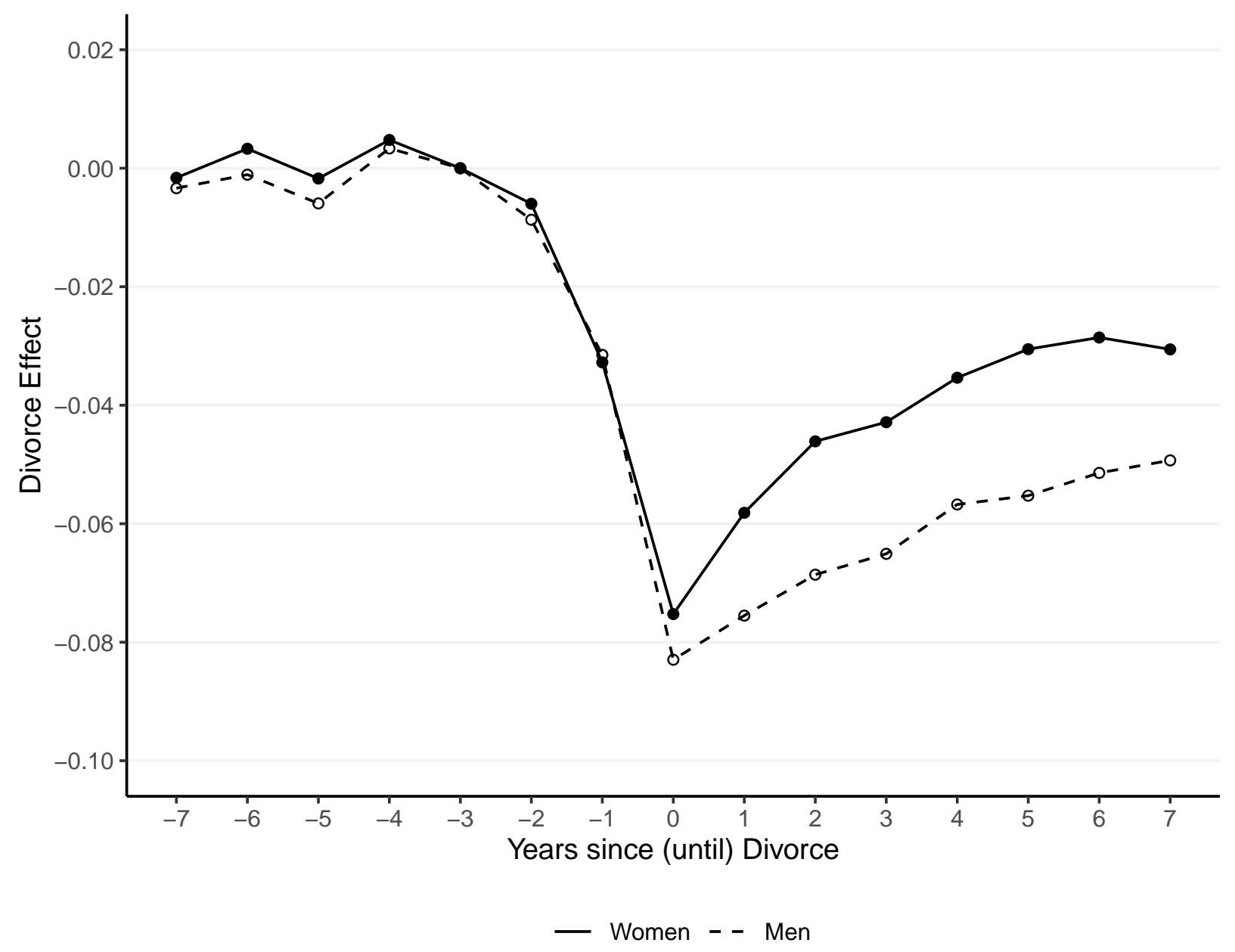

Figure A.4: Results with Individual Fixed Effects

\section{Logit Results}

In the main text we use a linear probability model to estimate the effects of interest. To check the robustness of these results we have re-estimated our main model using a fixed effects logit model. To do so we use the pseudo-demeaning algorithm with bias-correction (to deal with incidental parameter bias) developed by (Stammann et al., 2016). A downside with the fixed effects logit model is that we are forced to drop all couples in which there is no variation in voting behavior over time. As a consequence of this, the sample size is reduced by two-thirds. This notwithstanding, as can be seen from Figure A.6, the pattern of the average marginal effects based on the logit model results closely resembles the corresponding effects estimated using the linear probability model reported in the main text. 


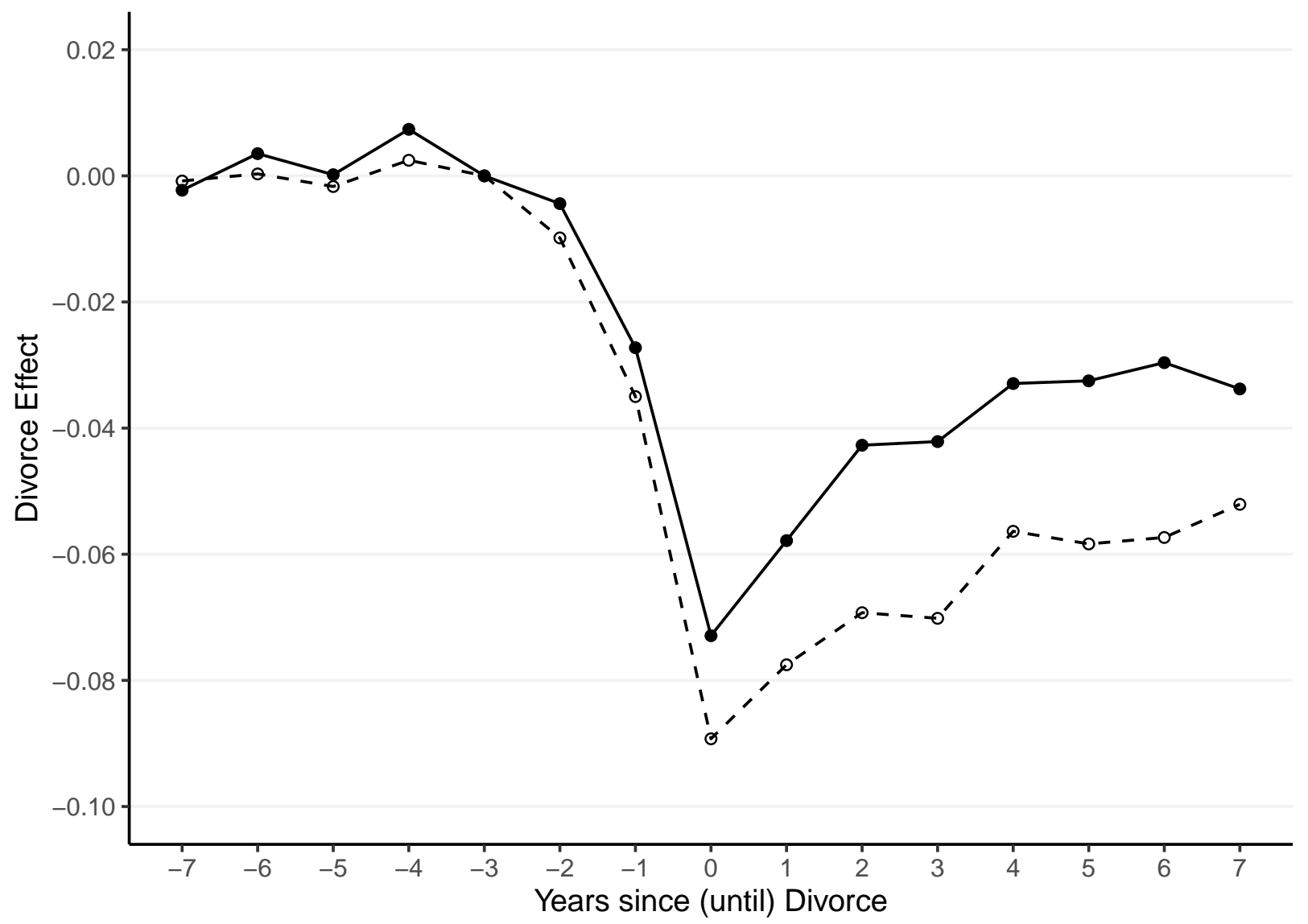

- Women - Men

Figure A.5: Results for Completely Observed Couples

\section{Divorce Effects by Parental Turnout}

In the main text we report how the divorce effect varies with the previous political activity of the spouses. As an alternative we may test how the divorce effect varies with the political activity of the parents of the spouses. In Figure A.7 we split our sample into groups based on the voting behavior of the divorcing spouses' parents. High parental turnout indicates that both parents voted in all election for which we have data, whereas low parental turnout indicates that at least one of the parents abstained from voting in at least one election.

Even if the results are less clear-cut, the main finding from Figure 6 in the main text is discernible also in Figure A.7. That is, the gendered divorce effect on voter turnout is moderated by the political activity of the spouses' parents. More precisely, when the 


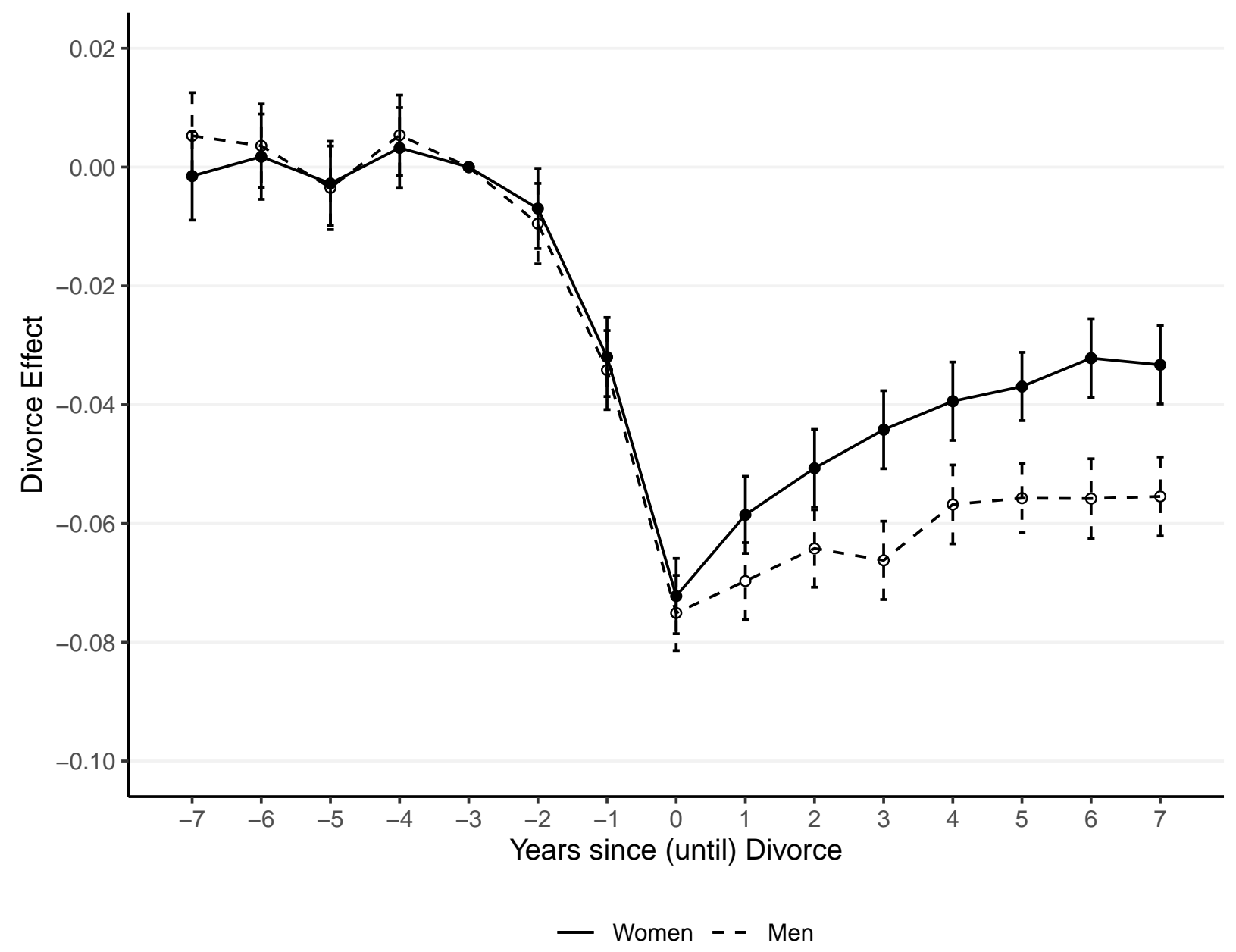

Figure A.6: Marginal Effects, Logistic Regression

husbands' parents are inconsistent voters (the upper right panel) the divorce effect is much more pronounced among males. However, when the wife's parents are less active (the lower left panel) the negative effect of divorce is instead is stronger among females (however, only marginally so).

\section{References}

Lindgren, Karl-Oskar, Sven Oskarsson, and Mikael Persson (2019). "Enhancing Electoral Equality: Can Education Compensate for Family Background Differences in Voting Participation?" en. In: American Political Science Review 113.1, pp. 108-122. 


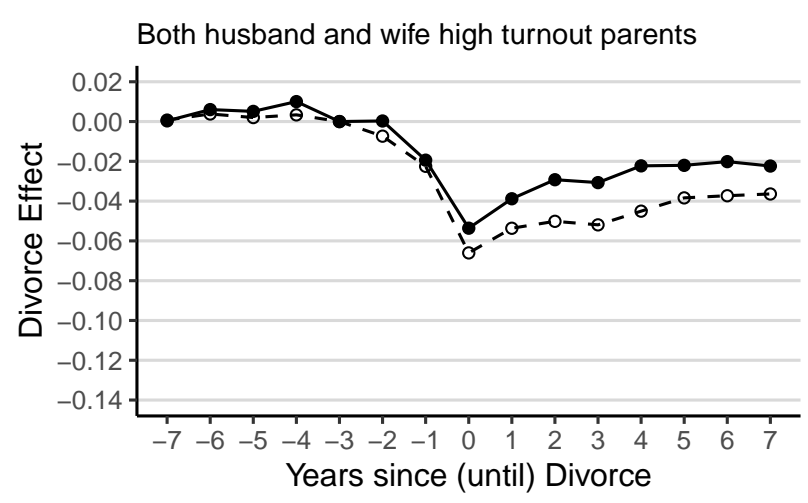

Husband high and wife low turnout parents

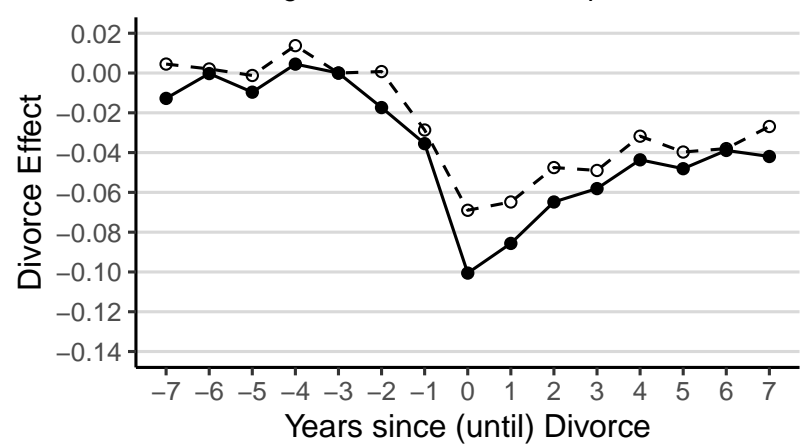

Husband low and wife high turnout parents

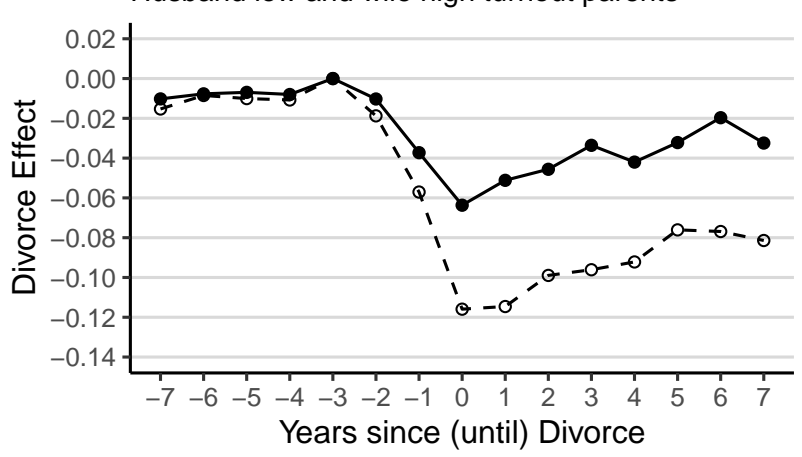

Both husband and wife low turnout parents

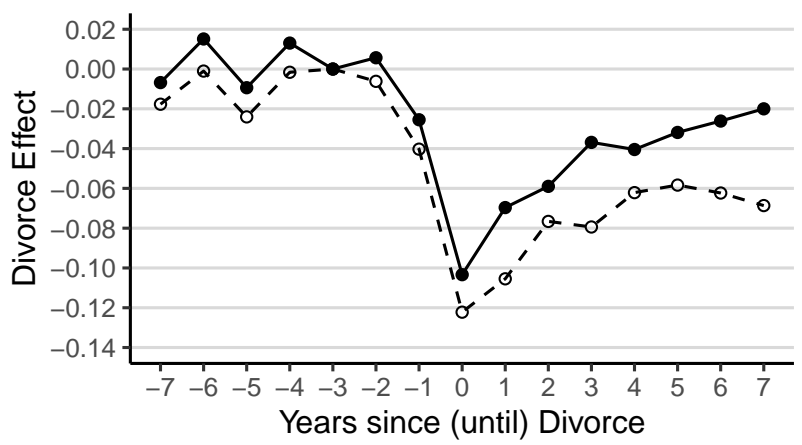

- Women - - Men

Figure A.7: Divorce Effect by Parental Turnout

Stammann, Amrei, Florian Heiß, and Daniel McFadden (2016). "Estimating Fixed Effects Logit Models with Large Panel Data”. eng. In: Beiträge zur Jahrestagung des Vereins für Socialpolitik 2016: Demographischer Wandel - Session: Microeconometrics. Issue: G01V3. Kiel und Hamburg: ZBW - Deutsche Zentralbibliothek für Wirtschaftswissenschaften, Leibniz-Informationszentrum Wirtschaft. 